\title{
TRENDS, BENEFITS, AND BARRIERS OF UNMANNED AERIAL SYSTEMS IN THE CONSTRUCTION INDUSTRY: A SURVEY STUDY IN THE UNITED STATES
}

\author{
SUBMITTED: September 2020 \\ REVISED: January 2021 \\ PUBLISHED: March 2021 \\ EDITOR: Robert Amor \\ DOI: $10.36680 /$ j.itcon.2021.006
}

Gilles Albeaino, PhD Student,

Rinker School of Construction Management, University of Florida, Gainesville, FL, USA; galbeaino@ufl.edu

\author{
Masoud Gheisari, Assistant Professor, \\ Rinker School of Construction Management, University of Florida, Gainesville, FL, USA; \\ masoud@ufl.edu
}

SUMMARY: Unmanned Aerial Systems (UASs) have rapidly been integrated into the construction industry over the past few years, and their application is continually growing in this domain. The recent development in UAS regulations and technical capabilities have played a significant role in their popularity and wide deployment in various stages of the construction lifecycle. UASs could be used as a platform to enhance the construction practices in general; however, little is known about how construction professionals are adopting this technology in specific construction practices and the barriers they are facing for their successful implementation. The purpose of this study is to explore the current state-of-practice of UAS integration in construction from the industry professionals' viewpoint. A comprehensive survey study was conducted in the United States to identify the practical construction UAS application areas, their adopted technologies, as well as the benefits and barriers encountered during their implementation. Responses $(n=56)$ showed that most common UAS applications include progress monitoring, site planning, and site surveying/mapping. Rotary-wing vehicles and visual and thermal cameras were the most used platforms and onboard sensors, respectively. Saving time, improving accessibility to compromised spaces, and reducing cost while accomplishing construction tasks were highly regarded as UAS implementation benefits in construction. Participants also considered flying in various weather conditions, within confined or congested areas, as well as the advanced technical know-how requirements, and the increased liability and legal challenges as barriers to using UASs in construction-related tasks. By understanding UAS adoption in construction, this study provides a roadmap to better identify the industry needs and guide researchers and professionals in investigating application areas and barriers that might have maximum benefits for the construction industry in the United States.

KEYWORDS: UAS, Unmanned Aerial Systems, Construction, Applications, Trends, Technologies, UAV, Drone

REFERENCE: Gilles Albeaino, Masoud Gheisari (2021). Trends, benefits, and barriers of unmanned aerial systems in the construction industry: a survey study in the United States. Journal of Information Technology in Construction (ITcon), Vol. 26, pg. 84-111, DOI: 10.36680/j.itcon.2021.006

COPYRIGHT: () 2021 The author(s). This is an open access article distributed under the terms of the Creative Commons Attribution 4.0 International (https://creativecommons.org/licenses/by/4.0/), which permits unrestricted use, distribution, and reproduction in any medium, provided the original work is properly cited. 


\section{INTRODUCTION}

Unmanned Aerial Systems (UASs), also known as drones or UAVs, are remotely piloted aerial platforms equipped with several onboard sensors (Hassanalian and Abdelkefi 2017). Initially employed for military purposes, these devices have recently witnessed remarkable technical improvements in terms of software and hardware components, and in response, their civilian applications have significantly increased over the last few years. Some examples of such applications are in infrastructure management (e.g., infrastructure inspection, building inspection), traffic surveillance, agriculture (e.g., crop health monitoring and assessment, soil analyses), material transport (e.g., delivery of food, medical supplies, parcels), search and rescue operations, as well as security surveillance (Shakhatreh et al. 2019). In the United States, it is anticipated that the UAS commercial market will have a yearly impact of more than $\$ 30$ billion by 2026 (McKinsey\&Company 2017).

AEC (Architecture, Engineering, and Construction) industry has also incrementally adopted UAS technology (Albeaino et al. 2019). UASs have been used in a variety of AEC applications from traffic surveillance (Barmpounakis and Geroliminis 2020; Hart and Gharaibeh 2011) and landslide monitoring (Niethammer et al. 2012; Yeh and Chuang 2020), to cultural heritage conservation (Enríquez et al. 2020; Koutsoudis et al. 2014; Uysal et al. 2013) and city planning (Banaszek et al. 2017; Bulatov et al. 2011). Construction, in particular, witnessed an exponential growth in UAS applications, the implementation of which stems from the benefits associated with their capability to access unreachable or unsafe areas, and their ability to perform tasks safely and time-efficiently (Gheisari and Esmaeili 2019; Zhou and Gheisari 2018). In addition, UASs' recent developments in terms of regulation updates, low acquisition costs, enhanced navigation features, autonomous flight capabilities, increased battery life, and variety types of onboard sensors, have played a significant role in their popularity and wide deployment in the construction industry (Hassanalian and Abdelkefi 2017; Zhou and Gheisari 2018). UASs can be adopted through different phases of a construction project from site surveying and mapping (Martinez et al. 2021a; Neitzel and Klonowski 2012) and progress monitoring (Álvares and Costa 2019; Unger et al. 2014) to building inspection (Eiris et al. 2020; González-deSantos et al. 2020; Hallermann et al. 2015a; Hallermann et al. 2015b), and structures maintenance (Mutis and Romero 2019). A significant amount of research has been done about how UAS technology can be used for specific construction-related tasks; however, understanding how the construction industry is incorporating such technology in their day-to-day practices is yet to be investigated.

Currently available survey questionnaires evaluating the practical use of UAS technology in construction based on the industry professionals' perspectives are very scarce. Kim et al. (2016) developed a questionnaire to understand the construction professionals' viewpoint regarding several UAS-related factors that would affect this technology's performance in safety management tasks. The study also highlighted some of the benefits and barriers to UAS integration in safety control tasks and ranked them in terms of importance based on participants' responses. Other more recent questionnaires with a higher population sample focused on the current and future potential use of UASs in construction, as well as the risks encountered and benefits associated with this technology's deployment in this domain (Hubbard and Hubbard 2017; Tatum and Liu 2017). Lately, Gheisari and Esmaeili (2019) targeted construction safety managers to evaluate the UAS technology's potential in improving safety applications and recommended the ideal UAS technical features as well as the enablers and barriers to using UASs in this setting. However, two of these studies focused only on using UASs in the aspect of construction safety management (Gheisari and Esmaeili 2019; Kim et al. 2016), and none had targeted a specific population of construction professionals who had previously used UASs on the jobsites. This is particularly important, as getting insights from such targeted population would accurately reflect the current state of UAS technology based on people who have actually used this technology together with its technical components and configurations on their construction jobsites, and noticed the benefits associated and barriers encountered with its implementation. In addition, none of these studies had fully identified: (1) current trends in real-world UAS applications throughout the entire construction lifecycle; (2) commonly used technologies by industry practitioners (i.e., UAS vehicle types, incorporated software tools, flight autonomy features, mounted sensors, and types of retrieved data); and (3) current flight training, insurance status, and UAS flight team composition.

The following study bridges the gap between the theoretical and practical implementation of UASs in construction across the United States. It provides a timely extension to previous conceptual-based efforts (Albeaino et al. 2019; Golizadeh et al. 2019a; Golizadeh et al. 2019b; Zhou and Gheisari 2018) by presenting, through empirical observations, how UASs are being employed by construction professionals who had previously used this technology on their jobsites. The study investigates the UAS implementation status in the construction industry 
by identifying their real-world application trends, technologies, benefits, and barriers commonly encountered by industry practitioners and highlights this technology's adoption in current practices. It also explores current flight training, insurance status, and flight team composition associated with the UAS deployment in construction. More specifically, this study addresses the following research questions: (1) What are the current application trends of UASs in the construction industry? (2) What are the technology trends of UAS integration in construction? (3) What are the benefits of UAS integration in construction? and (4) What are the barriers to UAS integration in construction? The analysis was achieved at first by exhaustively reviewing current literature to identify recent construction-related UAS application areas and technology use. Then, a comprehensive data collection instrument was designed and distributed across industry professionals in the United States to collect and analyze trends, benefits, and barriers to UAS integration in construction. The contribution of this research is to assist academic and industry experts in better understanding the apparatus and its technicalities, ultimately paving the way for a more effective UAS integration in the construction domain.

\section{BACKGROUND}

\subsection{UAS Application Areas}

UAS integration strongly affected current practices within the construction industry. UASs can be adopted for a variety of applications throughout different construction phases from pre-construction to construction, and even post-construction.

\subsubsection{Pre-Construction Applications}

Site mapping and surveying and site planning are the two common types of pre-construction applications that might benefit from UASs. Site mapping and surveying consist of collecting spatial and temporal information of jobsites before excavation. Traditional site surveying techniques rely mostly on terrestrial laser scanners, light detection and ranging (LiDAR) devices, GPSs, and total stations (Hugenholtz et al. 2015). The enormous acquisition costs of such devices and the time required for complex site surveying have paved the way to integrate UAS as an efficient alternative (Hugenholtz et al. 2015). As an example, Neitzel and Klonowski (2012) relied upon low-cost UASs to map an area composed of a landfill and a parking lot with the aim of performing comparative analyses between the point clouds generated by several data processing software tools. The authors advocated the use of UAS technology for site surveying applications and indicated that the average positional and height error values mainly depend on the topography of the surveyed area. The same area was assessed later by Siebert and Teizer (2013), who implemented a more accurate approach that resulted in a significant error reduction. The authors indicated that the error would have been lower should a more advanced UAS with higher quality camera be used. More recently, Martinez et al. (2021a) conducted comparative analyses between a commercially available UAS and another dual-frequency GPS platform with post-processing kinematic (PPK) georeferencing capabilities for site surveying types of applications. After evaluating the effects of different technical configurations (i.e., dual-frequency GPSs, PPK GPS correction) and flight parameters (i.e., image combinations, camera angle) on the accuracy and visual quality of the derived point clouds, the authors advocated the usage of UAS technology for site surveying and proposed a matrix summarizing the levels of point cloud accuracies with respect to the processing time and adopted technical configurations. UASs have also been used for site planning purposes that usually require extensive knowledge of on-site conditions, location, and surroundings. Beside utilizing construction and layout drawings, traditional planning and scheduling techniques often require project managers to walk the jobsite and collect relevant information (Zhou et al. 2018). With the deployment of UASs, site planners have become able to collect visual information to assist them plan construction activities and provide detailed schedule, layout, and logistics-related information, particularly when integrated with augmented reality (AR) (Wen and Kang 2014). Using UAS visualizations, a very recent analysis reconstructed a petrochemical plant to improve the hoist layout planning efficiency, ultimately resulting in faster, safer, and more efficient operations on the jobsites (Jiang et al. 2020a). Based on several layout plans generated using a specific algorithm, the authors recommended an optimized and weighted site plan to improve hoisting operations' safety and efficiency.

\subsubsection{Construction Applications}

UAS employment during construction stage can affect several applications from building inspection and progress monitoring to material handling and security surveillance. Building inspection is defined as the evaluation of building condition for structural integrity assessment. UAS deployment offers the advantages of mitigating cost, 
time, and risk associated with typical inspection tasks (Liu et al. 2016). Traditional access methods for inspection are numerous, but mostly include elevating platforms and scaffolding (Liu et al. 2016). Their drawbacks encompass the time required for logistics, the safety hazards associated with elevated and hard-to-reach areas, and the expensive equipment acquisition, justifying the need for more innovative and affordable alternatives (Morgenthal and Hallermann 2014; Xu and Turkan 2018). As an example, Eschmann et al. (2012) equipped a UAS with high-resolution cameras for digital monitoring of buildings and crack detection and were able to accurately observe and identify damages of a facade to the millimeter range. The accuracy of this technology in inspecting buildings was also validated by comparing it to other, more conventional methods (Wefelscheid et al. 2011). Morgenthal and Hallermann (2014) used UASs to visualize and assess the condition of a stone-made church tower and its roof, a joint between a hangar wall and its roof, the core of a wind turbine, and a chimney for damage identification purposes. Despite being challenged by the environmental conditions, the authors encouraged the use of the UAS technology, as it allowed for a very close and detailed building damage detection while providing access to hard-to-reach areas. Using the same UAS-based non-destructive method, Hallermann et al. (2015b) inspected a cathedral and a tower to evaluate their conditions. Similarly to Morgenthal and Hallermann (2014), the results of this study showed that the high-quality images, together with the aerial platforms' capabilities of flying at a proximity of the buildings allowed for a very detailed building assessment, recommending UAS technology in this setting. UASs have been also used for structural inspection purposes in indoor environments. Kang and Cha (2018) utilized an Ultrasonic Beacon System (UBS) to autonomously operate their platforms in GPS-denied environments and were able to detect and localize indoor concrete damages accurately and precisely. More recently, González-deSantos et al. (2020) successfully developed and tested a UAS-payload system capable of operating independently from the platform's navigation and positioning system to improve current UAS-based structure inspections in indoor or GPS-deprived locations. Testing their system in both indoor and outdoor environments, the authors demonstrated the system's practicability in accomplishing semi-autonomous, stable, and bounce-free contact inspections.

UAS incorporation can also facilitate progress monitoring, which consists of tracking the progress of construction projects. Traditional supervision methods include walking and collecting terrestrial or satellite jobsite imagery but are limited by multiple factors. Some of the latter include the time required for manual jobsite surveillance and the environmental effects on the quality of the satellite images (Ezequiel et al. 2014; Zhou et al. 2018). UASs are characterized by enhanced flexibility, high-resolution imagery, and operational proximity, making building monitoring possible over multiple periods (Unger et al. 2014). For example, UASs were successfully deployed to monitor the construction progress of roads and bridges in a massive infrastructure development project (Ezequiel et al. 2014). Unger et al. (2014) relied on UAS-generated orthophotos to monitor small building-zoned areas with time and were able to accurately identify changes over a period of five months. Compared to traditional photogrammetry, the authors indicated that the use of UAS technology is an efficient alternative that is capable of accomplishing progress monitoring tasks in a cost- and time-effective manner. Through an automated collaborative framework, Park et al. (2018) combined an UAS with a ground robot with the aim of generating three-dimensional point clouds and visualize the construction jobsites. The results showed that the ground-robot combination improved the effectiveness of progress monitoring applications by reducing onsite human intervention, reducing the risks and time associated with traditional progress inspections. A more recent study integrated performance indicators and visual data technologies such as building information modelling (BIM) and UAS-derived products to improve current progress monitoring tasks on the construction jobsites (Álvares and Costa 2019). Despite encountering some limitations, the authors demonstrated the successful implementation of their proposed method on a real-world construction jobsite and noted that their technique is associated with enhanced collaboration and decision-making, planning failure detection, and jobsite visualization, ultimately improving jobsite monitoring tasks.

UAS deployment also has the potential to highly impact construction safety planning and monitoring applications. A construction environment is conventionally assessed by safety managers who are required to constantly walk and monitor jobsites to identify and modify unsafe practices. Site complexity and size as well as the limited number of safety managers and their accessibility to unsafe and hard-to-inspect areas of the site might jeopardize their overall performance and increase the risk of life-threatening consequences (Martinez et al. 2021b; Zhou et al. 2018). Therefore, UAS technology has the great potential to be used as a safety inspection assistant and provide frequent and quick inspection of construction sites. As an example, Roberts et al. (2017) utilized UASs equipped with object detectors to reduce crane-associated safety hazards. Using a dense 3D point cloud generated from 
UAS-acquired videos, Gheisari et al. (2018) proposed an automatic fall hazard identification model that allows the detection of openings and guardrails not conforming to the Occupational Safety and Health Administration (OSHA) safety standards. UAS-acquired visuals were also relied upon to identify several on-site components not meeting safety requirements (de Melo et al. 2017). Using a UAS-generated point cloud, Agung Pratama et al. (2018) visualized the interior of a typhoon-hit building and incorporated it into a virtual reality (VR) environment for post-disaster safety training purposes. The study advocated the use of UAS technology in this setting and concluded that the UAS-acquired visuals allowed for a faster and effortless site reconstruction. Recently, Martinez et al. (2020) integrated UAS technology in current safety management tasks with the aim of assisting safety managers in accessing difficult-to-reach and unsafe areas on jobsites. Despite mentioning several limitations that would hinder this technology's full deployment for safety applications, the authors emphasized on the UAS technology's potential in improving the detection and assessment of outdoor hazardous situations in high-rise construction projects.

UASs can also be used for construction earthwork operations and volume calculations. Siebert and Teizer (2014) compared UAS-mediated photogrammetry to conventional tachymetric techniques for earthwork calculations and advocated the use of UAS technology in this setting. Those results were validated by other researchers, who monitored the volume change of a gravel stockpile using UAS technology and real-time kinematic GPS surveying methods (Hugenholtz et al. 2015). Comparative analyses between UAS-based photogrammetry and conventional GPS-mediated surveying techniques were also conducted on a highway expansion project to evaluate the volume of earthwork change over time (Wang et al. 2017). Results showed that the average error difference between UASand GPS-based surveying methods were within the acceptable range found in the literature, recommending the use of UASs due to this technology's capability of accomplishing tasks effectively and in less time. More recently, Jiang et al. (2020b) relied on UAS-acquired visuals to perform earthwork volume calculation and monitoring of a foundation pit and showed that UAS-mediated technique is capable of accomplishing earthwork surveys in a more efficient and effortless manner compared to conventional methods.

Other construction stage applications in which UAS deployment could be of great potential include aerial construction, material handling, security surveillance, and site communication. Due to their operational flexibility and proximity to structures, UASs could be programmed using mathematical algorithms to construct tall and complex buildings without the need for conventional construction methods such as cranes and scaffolds (Zhou et al. 2018). Together with aerial construction, UASs could be used as material transportation and handling tool which, in contrast to conventional transportation equipment, can accomplish tasks more quickly and efficiently (Zhou et al. 2018). In this context, Lindsey et al. (2011) were able to autonomously control a team of UASs and perform aerial construction and transportation tasks such as picking up, moving, and assembling structural elements of a mock-up structure. Another study operated a team of autonomous UASs for collaborative material transport applications (Mellinger et al. 2010). Michael et al. (2011) also presented a payload transport method that is based on a swarm of autonomous UASs. The authors showed that the team of UASs is capable of effectively transporting payloads that could be otherwise difficult to be carried with single UASs. A collaborative work also explored the possibility of using UASs for the construction of full-scale masonry structures (Goessens et al. 2018). After designing several construction elements compatible with their customized UAS and testing the platform's design and performance by building several types of structures, the authors' results were encouraging in terms of potential use of UAS for aerial construction. However, current UAS models are limited in terms of payload weight and battery life, factors that restrict UASs to carry relatively heavy construction material. In addition, Choi and Kim (2019) recently relied on UAS technology as a new lifting and transportation means to improve current modular construction logistics and material handling challenges. Despite encountering several challenges such as the platform's instability, limited payload weight, and battery life, the tested platform-module system seemed promising in terms of construction project time and cost reduction. Security surveillance is another construction task that could be accomplished using UASs for stealing and trespassing protection on the jobsites (Zhou et al. 2018). Traditional site surveillance methods involve surveillance cameras and patrols that continuously monitor jobsites. Equipped with regular and thermal cameras, UASs are capable of reducing the need for security patrols, ensuring the secure storage of construction equipment, and detecting any potential breach from unauthorized individuals (Zhou et al. 2018). In this context, Bürkle et al. (2011) developed a team of autonomously operated UASs and simulated an intrusion scenario to test the system's effectiveness for security surveillance type of tasks. After presenting several scenarios that justify the need for a swarm of UASs, the study highlighted the importance of such swarms in monitoring and following intruders in case of any potential violation in the areas of interest. 
Bhandari and Park (2020) developed a security monitoring system that combines UASs, computer vision, and deep learning for intruder detection and surveillance in restricted areas. Despite not testing their proposed method in a construction jobsite intrusion scenario, the authors showed that the system is capable of precisely identifying intruders and notifying site managers in real-time via cloud-based message service, factors that ultimately improve the detection and response efficacy associated with any intrusion threats. UASs could also be equipped with onboard transmitters for site communication purposes. Not only would this task enhance project performance in general, but it offers managers the ability to communicate in real-time with construction workers and prevent, for example, safety accidents on jobsites (Irizarry et al. 2012). As an application example, Schneegass et al. (2014) equipped an UAS with a remotely controlled iPad to explore the concept and potential benefit of mid-air displays and presented several scenarios to which such configuration could be of significant value. A more recent study built on the results of previous research exploring mid-air display systems (Scheible and Funk 2016; Schneegass et al. 2014) by designing a programming toolkit that developers could utilize to create multimedia applications specifically intended for such type of systems (Lingamaneni et al. 2017). The authors successfully demonstrated the practicability of their proposed toolkit by developing an application allowing mid-air displays to communicate and display specific media content to viewers based on the platforms' location. With such system on construction jobsites, professionals would ideally be able to communicate and share information with workers from farther distances, in a more efficient, simultaneous, and prompt manner.

\subsubsection{Post-Construction Applications}

Post-disaster assessment and building maintenance are the two common types of post-construction stage applications that might benefit from UASs. Post-disaster assessment involves the evaluation of damage endured in buildings following natural events. In such extreme cases, it would be difficult and dangerous for inspectors to assess buildings' conditions. While other traditional techniques such as satellite imagery are somewhat effective in covering large areas, their spatial resolution limits their employment on individual buildings or smaller-scale areas (Adams et al. 2014). For example, Kruijff et al. (2012) combined aerial and ground robots to safely assess the damage that several structures suffered during an earthquake in Italy. The combination of aerial-ground robots was also deployed by Michael et al. (2012) to survey the indoor of an earthquake-hit building in Japan. Despite mentioning several factors encountered during their field experiment (e.g., restricted UAS accessibility to some areas in the damaged building, UAS operation in GPS-denied environments, UAS robustness and performance in post-disastrous and dusty environments), the authors were able to provide two- and three-dimensional maps of the surveyed area and identified several damaged features in this setting. UAS imagery also provided detailed information about damaged structures, their structural material and components, as well as their failure mechanism (Adams et al. 2014). Recently, Zhang et al. (2020) proposed a four-step automatic building damage identification and information extraction technique using UAS-acquired oblique thermal images. After testing their system on earthquake-affected buildings, the authors advocated the usage of UASs for post-disaster assessment and showed that their method provided a damage detection accuracy of around $80 \%$. Building maintenance applications include activities related to the operation and maintenance of buildings such as roof or facade inspection which usually happen during the post-construction stage of projects. Facility managers maintaining the functionalities of buildings mainly deal with accessibility challenges to unsafe or hard-to-inspect areas. In addition, the time and cost associated with typical inspection tasks are high and should be carefully considered. UAS technology could possibly be deployed as an efficient tool for building maintenance due to the platform's operational flexibility, reducing safety hazards and time associated with conventional assessment methods. As an example, Liu et al. (2016) conducted comparative analyses between UAS- and LiDAR-generated point clouds of a building curtain wall with the aim of assessing its current condition and concluded that UAS technology is capable of accomplishing such type of tasks safely and cost-efficiently. Chen et al. (2021) proposed a two-step Geographical Information System-based method to automate management and documentation of UAS-acquired data for building facade damage inspection and maintenance applications. Through their building case study, they showed that their proposed technique was practical and capable of geo-registering UAS images effectively, factors that ultimately assist construction personnel in the decision-making process of future building maintenance and retrofitting tasks. Other UAS-mediated building maintenance application examples include: (1) conducting energy analyses by surveying building facades using a Microsoft ${ }^{\circledR}$ Kinect sensor mounted on the aerial platform (Roca et al. 2013); and (2) assessing the thermal performance of building envelopes using infrared thermography to detect and evaluate thermal bridges within facades (Mutis and Romero 2019). Table 1 highlights the results obtained from the literature review. 
TABLE 1: Potential UAS application areas

\begin{tabular}{|c|c|c|}
\hline Application Area & Description of Application Area & Citations \\
\hline $\begin{array}{l}\text { Site Mapping and } \\
\text { Surveying }\end{array}$ & $\begin{array}{l}\text { Collecting information of the construction sites prior to } \\
\text { excavations. }\end{array}$ & $\begin{array}{l}\text { Martinez et al. (2021a); Neitzel and Klonowski } \\
\text { (2012); Siebert and Teizer (2013) }\end{array}$ \\
\hline Site Planning & $\begin{array}{l}\text { Planning site activities with detailed schedule, layout, and } \\
\text { logistics. }\end{array}$ & Jiang et al. (2020a); Wen and Kang (2014) \\
\hline Building Inspection & Evaluating buildings' structural integrity and damage. & $\begin{array}{l}\text { Eiris et al. (2020); Eschmann et al. (2012); } \\
\text { González-deSantos et al. (2020); Hallermann et al. } \\
\text { (2015a); Hallermann et al. (2015b); Hallermann } \\
\text { and Morgenthal (2013); Kang and Cha (2018); } \\
\text { Morgenthal and Hallermann (2014); Wefelscheid } \\
\text { et al. (2011) }\end{array}$ \\
\hline Progress Monitoring & Monitoring construction activities on jobsites. & $\begin{array}{l}\text { Álvares and Costa (2019); Ezequiel et al. (2014); } \\
\text { Irizarry and Costa (2016); Park et al. (2018); } \\
\text { Unger et al. (2014) }\end{array}$ \\
\hline Safety Management & Protecting construction workers against safety hazards. & $\begin{array}{l}\text { Agung Pratama et al. (2018); Gheisari et al. } \\
\text { (2018); Martinez et al. (2020); de Melo et al. } \\
\text { (2017); Roberts et al. (2017); Martinez et al. } \\
\text { (2021b) }\end{array}$ \\
\hline Earthmoving & $\begin{array}{l}\text { Assisting in excavation and earthwork volume } \\
\text { calculations. }\end{array}$ & $\begin{array}{l}\text { Hugenholtz et al. (2015); Jiang et al. (2020b); Kim } \\
\text { et al. (2015); Siebert and Teizer (2013); Siebert } \\
\text { and Teizer (2014); Wang et al. (2017) }\end{array}$ \\
\hline Aerial Construction & Aerially constructing buildings. & Goessens et al. (2018); Lindsey et al. (2011) \\
\hline Material Handling & Transporting construction material and tools. & $\begin{array}{l}\text { Choi and Kim (2019); Goessens et al. (2018); } \\
\text { Lindsey et al. (2011); Mellinger et al. (2010); } \\
\text { Michael et al. (2011) }\end{array}$ \\
\hline Security Surveillance & $\begin{array}{l}\text { Protecting against theft and trespassing on construction } \\
\text { sites. }\end{array}$ & Bhandari and Park (2020); Bürkle et al. (2011) \\
\hline Site Communication & Interacting with workers using onboard transmitters. & $\begin{array}{l}\text { Lingamaneni et al. (2017); Scheible and Funk } \\
\text { (2016); Schneegass et al. (2014) }\end{array}$ \\
\hline $\begin{array}{l}\text { Post-disaster } \\
\text { Reconnaissance }\end{array}$ & $\begin{array}{l}\text { Inspecting, communicating, or transporting materials on } \\
\text { damaged construction sites. }\end{array}$ & $\begin{array}{l}\text { Adams et al. (2014); Kruijff et al. (2012); Michael } \\
\text { et al. (2012); Zhang et al. (2020) }\end{array}$ \\
\hline Building Maintenance & $\begin{array}{l}\text { Maintaining functionalities of buildings during their life } \\
\text { span. }\end{array}$ & $\begin{array}{l}\text { Chen et al. (2021); Liu et al. (2016); Mutis and } \\
\text { Romero (2019); Roca et al. (2013) }\end{array}$ \\
\hline
\end{tabular}

\subsection{UAS Technology}

Accomplishing flight missions for construction application depends on several technical aspects of UASs that need to be considered: (1) selecting an appropriate aerial platform type, (2) choosing the appropriate flying style and incorporating proper UAS software tools for navigation and data processing purposes, and (3) selecting the appropriate data collection sensors for specific applications. As a result, understanding the implications of UAS configurations and technical components on the flight mission is of great importance for the successful integration of UASs in the construction domain. Two types of UAS vehicles have commonly been used in the construction domain: rotary-wing and fixed-wing. Rotary-wing vehicles are characterized by their abilities to hover, vertically takeoff and land, and are known for their flexibility and safe deployment due to their engines' redundancy (Ellenberg et al. 2014). Rotary-wing UASs can be helicopters or multi-copters, depending on the number of the propellers outfitted on the platform. Rotary-wing characteristics make them a potentially better platform for smallto-medium size projects or vertical types of construction. Fixed-wing vehicles are remotely piloted aircrafts known by their long flight endurance and abilities to survey large areas (Albeaino et al. 2019). Such capabilities make them a better platform for large size projects or horizontal construction. Fixed-wing's main limitations are hovering incapability and the need for runways to takeoff and land (Zhou and Gheisari 2018). Table 2 describes the types of UAS vehicles utilized in construction along with some application examples. 
TABLE 2: Common UAS vehicle types

\begin{tabular}{|c|c|c|}
\hline Vehicle Types & Characteristics & Related Applications (Citations) \\
\hline \multirow{5}{*}{ Rotary-wing } & \multirow{5}{*}{$\begin{array}{l}\text { - } \quad \text { Composed of one or multiple propellers. } \\
\text { - } \quad \text { Do not require runways, as they can takeoff and land } \\
\text { vertically. } \\
\text { - } \quad \text { High hovering capabilities. } \\
\text { - } \quad \text { Considered safe and stable due to propellers } \\
\text { redundancy. } \\
\text { - Low flying endurance. }\end{array}$} & $\begin{array}{l}\text { Structural Inspection: (Hallermann et al. 2015a; } \\
\text { Hallermann et al. 2015b) }\end{array}$ \\
\hline & & $\begin{array}{l}\text { Earthwork Calculations: (Hugenholtz et al. 2015; } \\
\text { Jiang et al. 2020b; Siebert and Teizer 2014) }\end{array}$ \\
\hline & & $\begin{array}{l}\text { Progress Monitoring: (Álvares and Costa 2019; } \\
\text { Unger et al. 2014) }\end{array}$ \\
\hline & & $\begin{array}{l}\text { Post-Disaster: (Adams et al. 2014; Zhang et al. } \\
\text { 2020) }\end{array}$ \\
\hline & & $\begin{array}{l}\text { Building Maintenance: (Kim et al. 2019; Roca et al. } \\
\text { 2013) }\end{array}$ \\
\hline \multirow[b]{2}{*}{ Fixed-wing } & $\begin{array}{ll}\text { - } & \text { Look similar to traditional aircrafts. } \\
\text { - } & \text { Require runways for takeoff/landing. }\end{array}$ & Post-Disaster: (Ezequiel et al. 2014) \\
\hline & $\begin{array}{l}\text { - } \quad \text { No hovering capabilities. } \\
\text { - } \quad \text { Popular for their ability to survey large areas. } \\
\text { - } \quad \text { High flight endurance. }\end{array}$ & Progress Monitoring: (Ezequiel et al. 2014) \\
\hline
\end{tabular}

UASs rely mostly on the incorporated software tools while accomplishing their intended tasks. These tools are used primarily for controlling the UAS vehicles, collaborating with UAS team members, processing images, and generating 3D models. UAS navigation styles consist of three distinct types: autonomous, semi-autonomous, and manual. Autonomous flight control relies entirely on autonomous features such as auto-return home, auto takeoff/landing, waypoint navigation, follow target, obstacle avoidance, and guarded motion. The Auto-return home is a feature that guarantees the safe return and landing of UASs to their home point (Siebert and Teizer 2014). This function is either automatically activated in case of signal loss and battery depletion, or manually triggered by the pilot. The automatic takeoff/landing function assists pilots in performing a safe UAS takeoff and landing (Michael et al. 2012). Waypoint navigation, in which UAS flight routes can be planned using defined GPS waypoints, is another autonomous UAS feature adopted in construction (Siebert and Teizer 2014). The follow target function assists operators in programming UASs to constantly follow and depict targeted objects. For example, the use of this feature could enhance safety managers' performance in terms of jobsite monitoring by providing real-time monitoring of targeted objects such as workers and machinery on site. Obstacle avoidance is another feature that depends on the incorporated sensors within the UAS. The usage of this function, especially in complex or indoor environments, is extremely efficient as it helps in detecting nearby obstacles and preventing UAS accidents (Duque et al. 2018). Autonomous UASs are also integrating the guarded motion, which is an intelligent safety feature that relies on the geofencing technique. This technique gives pilots the ability to create virtual navigational barriers and automatically control UASs within the defined boundaries. Besides autonomous control, semi-autonomous navigation combines pilot's decisions with autonomous features to accomplish flight missions, whereas manual navigation depends entirely on the pilot's focus and judgment. It should be noted that manual navigation does not involve any autonomous capabilities, factor that makes UAS operation and control more complicated and exhausting (Püschel et al. 2008). Table 3 describes the adopted UAS flying styles and examples of their application areas in the construction industry.

TABLE 3: UAS flying styles adopted in the construction domain

\begin{tabular}{|c|c|c|}
\hline Flying Styles & Description & Related Applications (Citations) \\
\hline Autonomous & 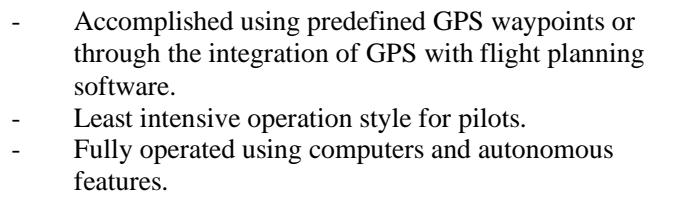 & $\begin{array}{l}\text { Structural Inspection: (Kang and Cha 2018) } \\
\text { Earthwork Calculations: (Hugenholtz et al. 2015) } \\
\text { Post-Disaster: (Ezequiel et al. 2014) } \\
\text { Progress Monitoring: (Ezequiel et al. 2014) }\end{array}$ \\
\hline $\begin{array}{l}\text { Semi- } \\
\text { Autonomous }\end{array}$ & $\begin{array}{l}\text { - Controlled using a combination of autonomous features } \\
\text { and manual (pilot) navigation. }\end{array}$ & $\begin{array}{l}\text { Structural Inspection: (Hallermann and Morgenthal } \\
\text { 2013) } \\
\text { Post-Disaster: (Michael et al. 2012) }\end{array}$ \\
\hline Manual & $\begin{array}{ll}\text { - } & \text { Most intensive operation style for pilots. } \\
\text { - } & \text { Fully operated through pilots. } \\
\text { - } & \text { No computer or autonomous intervention. }\end{array}$ & $\begin{array}{l}\text { Structural Inspection: (Eschmann et al. 2012) } \\
\text { Post-Disaster: (Adams et al. 2014) }\end{array}$ \\
\hline
\end{tabular}


Various types of sensors can be mounted on the UAS platform depending on the required type of data (e.g., image, video, audio) and specific application. Payload types range from readily available visual cameras, thermal cameras, or laser scanners and LiDARs to RFID (Radio Frequency Identification) readers or humidity, and temperature sensors. For example, thermal cameras were used to assess the thermal performance of structures (Mutis and Romero 2019) and maintain airports (Kim et al. 2019) whereas laser scanners and LiDARs were deployed for post-disaster building damage assessment (Michael et al. 2012), and the development of a beyond visual range guidance system for infrastructures inspection (Merz and Kendoul 2011), respectively. UBSs were deployed as an efficient GPS replacement for indoor structural inspections (Kang and Cha 2018) and RFID devices were relied upon to track materials on construction jobsites (Hubbard et al. 2015). Other types of utilized sensors include motion detectors, air quality devices, and audio sensors such as microphones. As an example, the Microsoft $®$ Kinect is an RGB-D motion capture device equipped with color and depth cameras, a motorized pivot, and a multiarray microphone. The Kinect sensor could be mounted on UASs for the real-time acquisition of spatial data, 3D scanning and modeling, as well as motion detection and monitoring purposes. Table 4 shows the utilized onboard sensors and some of their application areas in construction.

TABLE 4: UAS onboard sensors used in construction

\begin{tabular}{|c|c|c|}
\hline Onboard Sensors & Description & Related Applications (Citations) \\
\hline Visual Cameras & Used to collect regular images and videos. & $\begin{array}{l}\text { Structural Inspection: (Hallermann and Morgenthal } \\
\text { 2013) } \\
\text { Post-Disaster: (Adams et al. 2014) } \\
\text { Building Maintenance: (Kim et al. 2019; Liu et al. } \\
\text { 2016) }\end{array}$ \\
\hline Thermal Cameras & $\begin{array}{l}\text { - Thermographic cameras that sense infrared } \\
\text { radiation. } \\
\text { - Collect radiation with longer wavelengths than } \\
\text { visible light. }\end{array}$ & $\begin{array}{l}\text { Post-Disaster: (Zhang et al. 2020) } \\
\text { Building Maintenance: (Kim et al. 2019; Mutis and } \\
\text { Romero 2019) }\end{array}$ \\
\hline $\begin{array}{l}\text { LiDARs and Laser } \\
\text { Scanners }\end{array}$ & $\begin{array}{l}\text { - Capture surface shapes of objects or buildings } \\
\text { by using a line of laser beams. } \\
\text { - Used to generate digital 3D representations of } \\
\text { objects. }\end{array}$ & $\begin{array}{l}\text { Post-Disaster: (Kruijff et al. 2012; Michael et al. } \\
\text { 2012) } \\
\text { Building Maintenance: (Roca et al. 2013) }\end{array}$ \\
\hline $\begin{array}{l}\text { Radio Frequency } \\
\text { Identification Readers }\end{array}$ & $\begin{array}{l}\text { - An automatic identification and data capture } \\
\text { sensor. } \\
\text { - Used to identify, track, and collect information } \\
\text { pertaining to objects }\end{array}$ & Progress Monitoring: (Hubbard et al. 2015) \\
\hline
\end{tabular}

\subsection{UAS Regulations and Training Requirements}

The United States Federal Aviation Administration (FAA) institutes rules and regulations about using UASs within the national airspace system. To be able to use UASs for the commercial application in the United States, the operator has to be a certified remote pilot, at least 16 years of age and must register the aerial platform through FAA before conducting any flights (US Department of Transportation 2016). The FAA requires UASs to operate only over unpopulated areas, within the pilot's line of sight, and during daylight time (Kim and Irizarry 2019). The aerial platforms should not exceed 55 pounds (including payloads), fly over 400 feet above ground level or top of a structure, and faster than 100 miles per hour (US Department of Transportation 2016). However, waivers could be obtained for some specific restrictions, guaranteeing that the deployment can be accomplished safely (Herrmann 2018). Future regulation updates are expected to further alleviate UAS operational and flight restrictions in an attempt to enhance UAS integration in commercial applications. Current FAA regulations, however, do not require any prior practical knowledge or hands-on experience related to UAS flight and operation. Several studies have been conducted to develop UAS training tools or modules which incorporate both theoretical and practical knowledge of UAS flight operations (Eiris Pereira et al. 2018; Williamson III and Gage 2019). As an example, Eiris Pereira et al. (2018) created hands-on flight and data processing activities for construction students on UAS technology, its software and hardware components, and its integration with 3D modeling techniques such as BIM. UAS manufacturers such as DJI $®$, 3DR $®$, and Yuneec $®$ are also providing professional pilot training software and virtual flight simulators for training purposes. Such hands-on training could help users operate UASs safely and improve their successful implementation in the construction domain. 


\section{RESEARCH METHODS}

Three main tasks were performed to accomplish the objectives of this study. These included: (1) development of a survey instrument, (2) data distribution and collection, and (3) data screening and analysis. The following sections describe these tasks in detail.

\subsection{Survey Instrument}

The theoretical knowledge acquired from the literature review guided the authors in designing a questionnaire serving as a data collection instrument. Before its administration, the survey was carefully reviewed and pilotconducted among industry experts and selected professors within the M.E. Rinker, Sr. School of Construction Management at the University of Florida for relevancy and validity assessment.

The survey consisted of five sections, covering the aims of the study. The first section presented a brief introduction about the study and included the confidentiality policies as well as a consent form that needs to be approved by each participant. The second section contained questions related to the types of construction applications in which the respondents have incorporated UASs previously, with respect to the various stages of a project (preconstruction, construction, and post-construction). If they have applied UASs in construction and indicated as such, they would then be asked to rate the effectiveness and the frequency of the specific application(s). The third section contained questions pertaining to the technical features of the UASs, including the UAS platforms' types (e.g., rotary-wing, fixed-wing), manufacturers, models, types of data collected (e.g., image, video, audio), software tools incorporated, onboard sensors, autonomous features, and the level of human involvement. This section also asked about UAS training, FAA certification, and UAS insurance. Section four included questions related to the enablers and barriers to using UASs in construction. The fifth section contained questions focusing on the respondents' professional background, such as organizational role, years of experience in the industry, career positions, and construction licenses. Participants were also asked to identify their construction sectors, which involved buildings, infrastructure, light industry, and heavy industry.

\subsection{Data Collection Process}

The targeted population consisted of construction professionals who used UASs to accomplish constructionrelated applications across the United States. Due to this very narrowed-down target population and the various groups of construction professionals who might use this technology, identifying and contacting appropriate participants in the survey was challenging, and no specific directory, group, or email-list was available for such retrieval. Due to the hard-to-reach audience of this study, participants' recruitment was accomplished using the snowball sampling method. The search strategy of the snowball sampling consists of two steps: (1) identifying potential individuals in the targeted population who are interested in filling out the questionnaire; and (2) relying on those individuals' social networks to distribute the survey link and recruit other interested professionals (Sadler et al. 2010). This chain-referral sampling method constitutes a recruitment mechanism that allows targeting hardto-reach audience and keeps on reiterating until the required sample size is met (Valerio et al. 2016). In order to optimize the response rate as well as simplify respondents' data submission and collection, the questionnaire was designed online using the Qualtrics Survey Software (Qualtrics 2019). Qualtrics is a web-based tool that allows users to design and administer questionnaires, as well as collecting and analyzing their data (Yuan et al. 2014). The study was first approved by the University of Florida Institutional Review Board (UFIRB \#201801233), and then e-mails and LinkedIn messages were used to invite the construction professionals.

\subsection{Data Screening and Analysis}

A total of 98 responses were collected and then screened to exclude incomplete responses. After screening, 56 complete responses were eligible for inclusion in the study and further analysis using descriptive statistics was conducted on them. Participants were distributed across 22 states in the United States and Washington D.C., as shown in Table 5. Participants also rated that they had a high level of familiarity with UASs (Average: 4.04, $1=$ Very Low and $5=$ Very High) and around $75 \%$ of them had more than 5 years of construction industry experience.

In terms of licenses and certifications, respondents were professional engineers (PEs) (7\%), certified general contractors (CGCs) (5\%), licensed architects (4\%), associate constructors (4\%), and designated design-build professionals $(4 \%)$. The remaining included Professional Surveyors and Mappers, Leadership in Energy and Environmental Design (LEED) Accredited Professionals, Construction Health and Safety Technicians, and Safety 
Trained Supervisors, among others. Most of the respondents occupied construction manager and/or general contractor roles $(77 \%)$, followed by engineers (13\%), consultants $(11 \%)$, owners $(7 \%)$, and specialty/trade contractors (7\%). Other roles included architects or designers, innovation specialists and project coordinators. In terms of specific career position, most of the respondents were project managers or assistant project managers (57\%) followed by project engineers (32\%), VDC (virtual design and construction) team members (25\%), and superintendents $(11 \%)$. Others included laborers, project executives, consultants, foremen, architects, safety and health managers, surveyors, quality directors, operations managers, and vice-presidents. It should be noted that since some participants had various organizational roles or positions in different projects, the total percentage is greater than $100 \%$. In terms of the construction sector, the largest sector was buildings (88\%) (including communication centers, lodging facilities, offices, medical centers, scientific and technological buildings, maintenance facilities, car park facilities, recreational centers and gymnasiums, dining establishments/bars/night clubs, retail buildings, educational, storage and distribution spaces, single family detached, single family attached, large multi-family, detention centers, and special-purpose facilities), followed by infrastructure (38\%) (including transport facilities, dams, levees, floodways, channels, roads, bridges, marine facilities, navigation, mass transport systems, tunnels, public utilities such as electric, telecommunications, water, wastewater, garbage, gas and sewer distributions and networks), light industry (27\%) (including food, automotive, electronics, electrical equipment, consumer products, and pharmaceutical/drug manufacturing), and heavy industry (18\%) (including metals, petroleum, oil, and gas refining and processing, process chemical, mining, power generation plants and stations, oil exploration, as well as pulp and paper manufacturing).

TABLE 5: Respondent Demographics

\begin{tabular}{|c|c|c|}
\hline Parameter & Number & Percentage of Total \\
\hline \multicolumn{3}{|l|}{ Experience } \\
\hline Less than 5 years & 14 & $25 \%$ \\
\hline 5 to 10 years & 12 & $21 \%$ \\
\hline 11 to 20 years & 20 & $36 \%$ \\
\hline 21 to 30 years & 6 & $11 \%$ \\
\hline Over 30 years & 4 & $7 \%$ \\
\hline \multicolumn{3}{|l|}{ Licenses and Certifications } \\
\hline Professional Engineers & 4 & $7 \%$ \\
\hline Certified General Contractors & 3 & $5 \%$ \\
\hline Licensed Architects & 2 & $4 \%$ \\
\hline Associate Constructors & 2 & $4 \%$ \\
\hline Designated Design-Build Professionals & 2 & $4 \%$ \\
\hline Other & 9 & $16 \%$ \\
\hline \multicolumn{3}{|l|}{ Organizational Roles } \\
\hline Construction Managers/General Contractors & 43 & $77 \%$ \\
\hline Engineers & 7 & $13 \%$ \\
\hline Consultants & 6 & $11 \%$ \\
\hline Owners & 4 & $7 \%$ \\
\hline Specialty/Trade contractors & 4 & $7 \%$ \\
\hline Other & 4 & $7 \%$ \\
\hline \multicolumn{3}{|l|}{ Career Positions } \\
\hline Project Managers & 22 & $39 \%$ \\
\hline Project Engineers & 18 & $32 \%$ \\
\hline VDC Team Members & 14 & $25 \%$ \\
\hline Assistant Project Managers & 10 & $18 \%$ \\
\hline Superintendents & 6 & $11 \%$ \\
\hline Other & 34 & $61 \%$ \\
\hline \multicolumn{3}{|l|}{ Construction Sectors } \\
\hline Building & 49 & $88 \%$ \\
\hline Infrastructure & 21 & $38 \%$ \\
\hline Light Industry & 15 & $27 \%$ \\
\hline Heavy Industry & 10 & $18 \%$ \\
\hline
\end{tabular}




\section{RESULTS}

\subsection{Application Trends of UAS Integration in Construction}

This section aims to identify UAS application trends within the construction industry. In this context, practitioners were asked about the tasks in which they or their organizations have implemented UAS technologies (See Table 6). The analysis revealed that the most common UAS application was progress monitoring (84\%). UASs are capable of fully automating the visual site documentation process by providing a bird's eye view on construction jobsites while capturing high-quality visual contents of construction activities more frequently and at a remarkably low cost and time. Such characteristics would make UASs a popular platform for progress monitoring. Site planning (68\%) and site mapping and surveying (61\%) were the other popular UAS application areas in construction. In such applications, UAS would assist construction personnel in obtaining spatiotemporal information of the jobsite and help them better plan construction-related activities, schedules, and logistics. The least common application areas were aerial construction (14\%), security surveillance (9\%), material handling (7\%), and site communication (7\%). Technical limitations such as payload weight, battery life, and onboard sensors restrict UASs to carry heavy materials or equipment for aerial construction, transportation, and communication applications. It is also worth noting that FAA rules prohibit UAS operations during nighttime and out of visual line-of-sight which might currently limit its deployment as a security surveillance tool on construction jobsites. However, given the rate of technological advancements and regulation updates, it is more likely that these types of applications overcome the presented limitations and become more frequently implemented in the near future.

TABLE 6: UAS application areas within different construction phases

\begin{tabular}{llll}
\hline$\#$ & Areas of Application & Construction Phases & Frequency N (\%) \\
\hline 1 & Progress Monitoring & Construction & $47(84 \%)$ \\
\hline 2 & Site Planning & Pre-Construction & $38(68 \%)$ \\
\hline 3 & Site Mapping and Surveying & Pre-Construction & $34(61 \%)$ \\
\hline 4 & Earthmoving & Construction & $28(50 \%)$ \\
\hline 5 & Building Inspection & Construction & $27(48 \%)$ \\
\hline 6 & Safety Management & Construction & $18(32 \%)$ \\
\hline 8 & Building Maintenance & Post-Construction & $11(20 \%)$ \\
\hline 9 & Post-disaster Reconnaissance & Post-Construction & $10(18 \%)$ \\
\hline 10 & Aerial Construction & Construction & $8(14 \%)$ \\
\hline 11 & Security Surveillance & Construction & $5(9 \%)$ \\
\hline 12 & Material Handling & Construction & $4(7 \%)$ \\
\hline
\end{tabular}

Participants were then asked to rate the effectiveness and frequency of integrating UASs in their different application tasks. The objective was to better understand UAS adoption in the construction domain, and identify most frequent, effective, and important application areas in this setting. Participants provided their feedback on how effectively and frequently they used UASs in each specific application using Likert scales. The mean, average and standard deviation of the responses are summarized in Table 7. Top application areas that had more than ten number of responses were used in this analysis. Participants rated site mapping and surveying (average: $4.38 \pm$ 0.73 ) as the most effective application, followed by progress monitoring (average: $4.34 \pm 0.75$ ), and site planning (average: $4.21 \pm 0.73$ ). It is worth noting that the same three applications were also rated as the most common application areas of UASs (Table 7). The least effective applications were post-disaster reconnaissance (average: $3.70 \pm 0.64$ ), safety management (average: $3.61 \pm 0.89$ ), and building maintenance (average: $3.36 \pm 0.77$ ). Regarding the frequency of use, the least frequent applications were building maintenance (average: $2.50 \pm 0.67$ ) and post-disaster reconnaissance (average: $2.00 \pm 0.77$ ).

To better evaluate the results, an importance factor was introduced, calculated through multiplying effectiveness and frequency average ratings. This factor allows for assessing the significance of using UASs for various applications within the construction domain. The most important construction applications that can use UASs are progress monitoring (17.45), site mapping and surveying (15.98), and site planning (13.85). These findings are valuable as they provide researchers with a roadmap that illustrates the top UAS application areas in construction 
that need to be further explored. The least important applications were building maintenance (8.41) and postdisaster reconnaissance (7.40). Despite the extensive amount of research about these application areas in the literature (Zhou and Gheisari 2018), these low importance factor ratings can be justified by the nature and recurrence of these applications. For example, building maintenance typically involves operating UASs in indoor or GPS-deprived locations which limit their usage in such applications. Besides, using UASs for the assessment of buildings in the post-disaster setting is a less recurring application compared to the other ones, a factor that explains the lowest frequency rating (average: $2.00 \pm 0.77$ ) despite being ranked higher in terms of effectiveness (average: $3.70 \pm 0.64$ ).

TABLE 7: Effectiveness, frequency, and importance factor of integrating UASs in different application areas

\begin{tabular}{|c|c|c|c|c|c|c|}
\hline \multirow{2}{*}{$\#$} & \multirow{2}{*}{ Application Areas ${ }^{a}$} & \multicolumn{2}{|c|}{ Effectiveness $^{b}$} & \multicolumn{2}{|r|}{ Frequency $^{\mathrm{c}}$} & \multirow{2}{*}{$\begin{array}{l}\text { Importance } \\
\text { Factor }\end{array}$} \\
\hline & & Median & Average Rating ( $\sigma)$ & Median & Average Rating ( $\sigma)$ & \\
\hline 1 & Progress Monitoring & 4 & $4.34(0.75)$ & 4 & $4.02(0.89)$ & 17.45 \\
\hline 2 & Site Mapping and Surveying & 5 & $4.38(0.73)$ & 4 & $3.65(1.05)$ & 15.98 \\
\hline 3 & Site Planning & 4 & $4.21(0.73)$ & 3 & $3.29(1.00)$ & 13.85 \\
\hline 4 & Building Inspection & 4 & $4.12(0.64)$ & 3 & $3.19(0.98)$ & 13.11 \\
\hline 5 & Earthmoving & 4 & $3.93(1.00)$ & 3 & $3.18(1.20)$ & 12.49 \\
\hline 6 & Safety Management & 3 & $3.61(0.89)$ & 3 & $3.22(1.08)$ & 11.64 \\
\hline 7 & Building Maintenance & 4 & $3.36(0.77)$ & 3 & $2.50(0.67)$ & 8.41 \\
\hline 8 & Post-disaster Reconnaissance & 4 & $3.70(0.64)$ & 2 & $2.00(0.77)$ & 7.40 \\
\hline
\end{tabular}

${ }^{a}$ Applications with more than 10 responses

${ }^{b}$ Effectiveness $(1=$ not effective at all, $5=$ extremely effective $)$

${ }^{c}$ Frequency $(1=$ not frequent at all, $5=$ extremely frequent $)$

At the end of this part of the survey, the respondents were also asked to discuss their other UAS application areas using an open-ended section. First, $13(23 \%)$ respondents indicated that they used UASs for marketing- or presentation-related purposes. For example, two respondents described using UASs as a tool in the "project pursuit stage", in which UAS visualizations were particularly used for preparing presentations and proposals. Another participant also noted that UAS images and videos were integrated with building information models through video/photo overlay for marketing and presentation purposes. Second, 7 (13\%) respondents indicated that UASs had been used for quality control-related purposes. For example, six respondents described using UASs for documenting as-built conditions such as "in-slab elements prior to concrete pouring", "post tension cables", "slab penetrations", "utility location markings after being laid out by agencies", and "pre-pour embeds". Two respondents $(4 \%)$ discussed using UAS-generated 3D point cloud models and comparing them against building information models (e.g., clash detection) for accuracy and quality control purposes. Some other specific applications indicated by individuals were equipment inspection and accident prevention (e.g., cranes), warranty evaluation, final work assessment, project documentation, 4D construction schedule simulation, power line stringing, building fascia inspection, moisture detection, and airflow monitoring.

\subsection{Technology Trends of UAS Integration in Construction}

Identifying the technology trends of UAS integration is crucial for the successful adoption of UAS technology in the construction industry. The goal of this section is to provide further details on the UAS technological components (e.g., types, software, sensors, flight capabilities) integrated in the construction domain.

\subsubsection{UAS Types}

First, the respondents provided details on the types and models of UASs that were used in their construction applications. Rotary-wing vehicles were the most frequently employed type of platforms (80\%), followed by fixedwing ones with only six respondents $(11 \%)$ using them. As discussed earlier, the advantages of rotary-wing vehicles include their flexibility and their ability to vertically takeoff and land. These characteristics, combined with their hovering capabilities and safe usage due to their engines' redundancy, make their deployment efficient and popular for vertical types of construction. It should be noted that the majority of our respondents were from the building sector (88\%) with mainly vertical types of construction where rotary-wing might be a more suitable platform. Top manufacturer of the UAS that respondents used its platforms was DJI® (84\%), followed by 3DR ${ }^{\circledR}$ $(13 \%)$ and Skycatch® $(4 \%)$. In terms of UAS models, the DJI® Phantom (73\%) was the most commonly used platform, followed by DJI® Mavic (23\%), DJI® Matrice (20\%), and DJI® Inspire (18\%). 


\subsubsection{UAS Software}

In terms of software tools or platforms that respondents have incorporated in various UAS-related applications, DroneDeploy® was the most frequently used one (45\%) followed by Pix4D® (34\%), 3DR Site Scan $(18 \%)$, Skycatch ${ }^{\circledR}(14 \%)$, and Propeller ${ }^{\circledR}(9 \%)$ (See Table 8 ). It should be noted that percentages do not add up to 100 since some participants had used more than one platform. DroneDeploy ${ }^{\circledR}$ is a comprehensive UAS surveying and mapping solution that is popular due to its ability to simplify UAS-mediated processes which range from flight planning and coordination to data collection, processing, and collaboration. Pix4D® is another platform that has UAS flights planning and data processing capabilities with specific features for mapping and photogrammetric purposes. Possible justifications for their popularity in the construction domain could include their wide range of capabilities as well as their compatibility with various types of UAS models and other software packages.

\subsubsection{UAS Flight Autonomy Features}

This subsection discusses different UAS flight autonomy features that were used during the deployment within various construction applications (see Table 8). Auto-return home (88\%), auto takeoff/landing (86\%), and obstacle avoidance $(75 \%)$ were the most frequently used flight autonomy features in construction with an almost comparable adoption. The tremendous technical improvements, as well as the need for a simplified, yet safe UAS deployment, have paved the way to integrate such flight autonomy features in the majority of the low-cost off-theshelf UAS platforms. These results also reflect the high number of practitioners who are favoring the use of such levels of autonomy in UAS flights and navigation rather than conducting a fully manual operation. Least common features included guarded motion (34\%) and follow target (23\%). Their low ratings might be explained by the fact that such features are not yet provided on all UAS configurations and their application is usually restricted to very particular occasions. For example, follow target feature can be used to monitor movements of objects (e.g., equipment, machinery, cranes) or humans (e.g., workers) on the jobsite, and guarded motion feature is usually used for indoor types of applications.

TABLE 8: Top incorporated software tools and autonomous functions for UAS applications in construction

\begin{tabular}{ll}
\hline Incorporated Software Tools & Frequency N (\%) \\
\hline DroneDeploy® & $25(45 \%)$ \\
\hline Pix4D® & $19(34 \%)$ \\
\hline 3DR Site Scan® & $10(18 \%)$ \\
\hline Skycatch ${ }^{\circledR}$ & $8(14 \%)$ \\
\hline Propeller & $5(9 \%)$ \\
\hline
\end{tabular}

\begin{tabular}{ll}
\hline Autonomous Functions & Frequency N (\%) \\
\hline Auto-Return Home & $49(88 \%)$ \\
\hline Auto Takeoff/Landing & $48(86 \%)$ \\
\hline Obstacle Avoidance & $42(75 \%)$ \\
\hline Waypoint Navigation & $35(63 \%)$ \\
\hline Guarded Motion & $19(34 \%)$ \\
\hline Follow Target & $13(23 \%)$ \\
\hline
\end{tabular}

\subsubsection{UAS Sensors and Data Types}

In order to accomplish various construction tasks, users should mount different types of sensors on their aerial platforms and collect various types of data. This subsection aims to identify common types of onboard sensors and popular types of data acquired using UASs for construction applications. The outcomes of this analysis would help better understand the industry needs and direct researchers to further investigate various sensors and data types for their successful integration in the construction domain. In terms of data types, respondents indicated that UASs were mostly deployed to capture images (93\%) and videos (84\%), and only two respondents specified capturing audio information (4\%) (Table 9). In terms of sensor types, the most common ones were visual cameras (93\%) and thermal cameras (34\%) followed by motion detectors (9\%), LiDARs (7\%), audio sensors (7\%), RFID readers (4\%), Kinect sensors (4\%), and air quality sensors (2\%). Respondents reported no other specific types of data collection sensors in this section.

TABLE 9: Types of acquired data and onboard sensors for UAS applications in construction

\begin{tabular}{ll}
\hline Data Acquired Using UASs & Frequency N (\%) \\
\hline Images & $52(93 \%)$ \\
\hline Videos & $47(84 \%)$ \\
\hline Audio & $2(4 \%)$ \\
\hline
\end{tabular}

\begin{tabular}{ll}
\hline Onboard Sensors & Frequency N (\%) \\
\hline Visual Cameras & $52(93 \%)$ \\
\hline Thermal Cameras & $19(34 \%)$ \\
\hline Motion Detection Sensors & $5(9 \%)$ \\
\hline LiDARs & $4(7 \%)$ \\
\hline Audio Sensors & $4(7 \%)$ \\
\hline RFID Readers & $2(4 \%)$ \\
\hline Microsoft® Kinect Sensors & $2(4 \%)$ \\
\hline Air Quality Sensors & $1(2 \%)$ \\
\hline
\end{tabular}




\subsection{Benefits of UAS Integration in Construction}

Practitioners were asked to indicate their level of agreement on several factors that enhance UAS integration in the construction industry (See Table 10). The majority of these factors were identified in the literature. Study respondents strongly agreed that UASs are capable of reducing time (average: $4.39 \pm 0.94$ ) and cost (average: 4.27 \pm 0.97 ) in accomplishing construction tasks while improving access to compromised or difficult-to-reach spaces (average: $4.38 \pm 0.96$ ) on the construction sites. Low-acquisition costs of UASs and their flexible and locationindependent characteristics to quickly collect data from inaccessible or hard-to-reach areas could benefit construction practitioners to conduct their tasks on jobsites. Despite not being rated as high as previous factors, respondents also agreed that using UASs could improve the quality of their work (average: $3.93 \pm 1.00$ ) and reduce their safety concerns (average: $3.88 \pm 1.12$ ). UASs can be integrated with a variety of advanced software and hardware components to capture and generate highly accurate data that can be used for quality assessments. Such technical capabilities, combined with the UAS's ability to access unsafe or hard-to-reach areas, help to conduct better safety inspections and reduce safety concerns on the jobsites. However, it should be noted that having flying platforms on site might have their own safety challenges (e.g., UAS fall, struck-by) that require proper planning and attention for their safe integration in construction practices (Gheisari and Esmaeili 2019).

TABLE 10: Participants' level of agreement regarding the advantages of using UASs for a construction task

\begin{tabular}{|c|c|c|}
\hline \multirow{2}{*}{ Variables } & \multicolumn{2}{|c|}{ Level of Agreement $^{\mathrm{a}}$} \\
\hline & Median & Average Rating (б) \\
\hline Saves time & 5.00 & $4.39(0.94)$ \\
\hline Improves accessibility to compromised spaces & 5.00 & $4.38(0.96)$ \\
\hline Saves cost & 5.00 & $4.27(0.97)$ \\
\hline Improves quality of work & 4.00 & $3.93(1.00)$ \\
\hline Reduces safety concerns & 4.00 & $3.88(1.12)$ \\
\hline
\end{tabular}

${ }^{a}$ Level of Agreement $(1=$ Strongly Disagree and $5=$ Strongly Agree $)$

A reliability analysis using Cronbach's $\alpha$ (Cronbach 1951), which is one of the most popular methods used to measure the internal consistency among a set of items, was performed on the presented benefits (Tavakol and Dennick 2011). For this specific set of items, $\alpha$ was equal to 0.890 , which is greater than the acceptable limit for reliability and internal consistency (Hair et al. 2014; Taber 2018). A Pearson correlation analysis with a significance level $\leq 5 \%$ was also performed using RStudio (RStudio Team 2019) to test for any associations between the participants' responses to the advantages of UAS integration in the construction industry (FIG. 1).

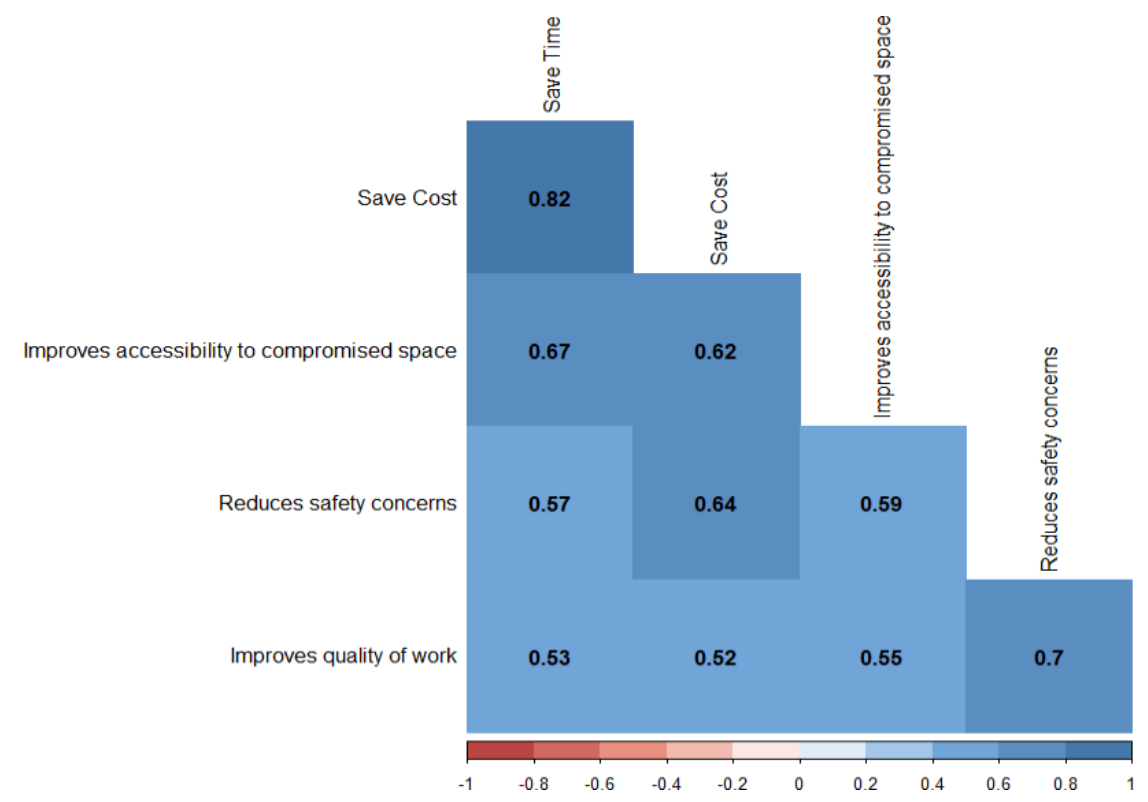

FIG. 1: Matrix diagram showing the correlations among the benefits of UAS integration in construction 
The Pearson correlation coefficient ( $\mathrm{r}$ ), having an absolute value ranging between 0 and 1, indicates the strength of linear dependency among the analyzed variables $(<0.2$ : very weak; $0.20-0.39$ : weak; $0.4-0.59$ : moderate; 0.6 - 0.79: strong; and $\geq 0.8$ : very strong correlation) (Evans 1996). At least moderate correlations $(0.4 \leq \mathrm{r}<0.59)$ were identified among all the benefits (FIG. 1). This shows that the construction practitioners were satisfied with UAS implementation regardless of the type of application for which the technology was used. A very strong correlation $(\mathrm{r}=0.82, \mathrm{p}<0.001)$ was identified between the "save cost" and "save time" benefits. While the majority of the current studies agree that UAS adoption saves time and cost, none of them evaluated the impact of using this technology in terms of time and cost with respect to conventional methods. This constitutes a critical research focus that warrants further investigation.

\subsection{Barriers to UAS Integration in Construction}

Respondents also provided their level of agreement on several barriers to UAS integration in construction (Table 11). It should be noted that none of the barriers were rated very high (i.e., more than 4) on average, which might be a positive indication of industry's progress in overcoming the difficulties of integrating UASs for construction applications. Participants agreed that flying in various weather conditions (average: $3.95 \pm 0.97$ ) and within confined or congested spaces (average: $3.88 \pm 0.80$ ) are the top two barriers to using UASs in construction-related tasks. Environmental conditions (average: $3.95 \pm 0.97$ ) such as inclement weather, lighting conditions, sunlight reflectivity, and wind speed, might negatively impact the aerial platforms' performance, the quality of the captured data, as well as the flight operation and safety. Moreover, UAS challenges in confined or congested spaces (average: $3.88 \pm 0.80$ ) might include indoor or outdoor areas that might cause navigational and operational difficulties associated with flights in the proximity of other obstacles (e.g., buildings, cranes, trees) or nearby metallic structures that could result in GPS deficiency and magnetic interferences. These issues should be carefully considered as they potentially render the task more complex and might cause extremely dangerous situations for workers and other construction entities on site. Participants also agreed that UASs integration in construction is challenged by the advanced technical know-how (average: $3.52 \pm 0.98$ ) associated with UAS technology. UAS flight team should have proper knowledge about UASs and be able to deal with technical issues that might occur throughout different flight tasks and environments. Examples of technical problems include signal loss, object interference, onboard sensor flaws, and battery life (Gheisari and Esmaeili 2019). Team members should also be familiar with data extraction and processing techniques to use the collected data for their specific tasks or decision makings. Increased liability and legal challenges (average: $3.48 \pm 1.12$ ) were also acknowledged by practitioners as barriers to using UASs in construction. Such barriers include a wide variety of issues that range from personal injury or property damage to ethical concerns, privacy invasions, and insurance issues. Although these aspects were not exhaustively investigated in the construction field, Herrmann (2016) considered privacy as one of the potential liability types encountered while using UASs on jobsites. Despite obtaining authorization from different project entities (e.g., owner, insurance providers) to operate UASs on site, privacy concerns might originate from nearby properties, residential community, or pedestrians who did not necessarily allow their movements to be monitored (Herrmann 2016). This is particularly important when it comes to civil liberty intrusions, especially since UASs are capable of acquiring images and videos in areas where people would expect to have some privacy, and at some locations and properties that could have been otherwise difficult to be seen using the human's naked eye (Finn and Wright 2012). Privacy is also considered an issue even when using UASs within the construction jobsite boundaries. While it could be beneficial to track the movement of construction workers using several technologies to enhance, for example, the productivity output on jobsites, workers might get influenced by the fact that they are being continuously monitored, and adjust their behavior accordingly (Gheisari and Esmaeili 2019; Herrmann 2016). As an example, Costin et al. (2012) faced some disruptive behavior by some of the workers who refused to cooperate and damaged some equipment while implementing RFID technology on site for resource productivity assessment purposes. The privacy concerns associated with UAS use on jobsites remain unsettled (Herrmann 2016); however, the increased adoption of UASs in construction will make workers more familiar with this technology and enhance its integration in this setting.

Participants also considered other variables as barriers affecting the use of UASs in construction. However, these barriers were rated lower than the ones reported above. One moderately rated barrier was the extensive training and certification $(3.34 \pm 0.95)$ required for the successful implementation of the aerial platforms in construction. To use the UASs for commercial applications, flight team members should include an FAA-certified remote pilot onboard. In addition to the FAA certification requirement, the type of work in construction requires pilots to be properly trained and skilled to safely fly the UAS in various types of spaces and conditions (e.g., indoor and 
outdoor sites, close to obstacles and structures, over active sites). It should be noted that FAA certification only includes a knowledge test and does not require any prior practical knowledge or hands-on experience related to UAS flight and operation (US Department of Transportation 2016). Implementing hands-on or practical training to ensure that pilots have acquired the proper skills to safely and assertively operate UASs should be integrated either internally in the trainings provided by construction companies or through changes in the FAA certification requirements. Another moderately rated barrier by survey participants, includes the use of UASs during nighttime $(3.32 \pm 1.12)$. Using UASs during nighttime is not a common practice and is limited only to specific applications or project needs. The current FAA rules restrict UAS operation at night, which is defined as: "the time between the end of evening civil twilight and the beginning of morning civil twilight" (US Department of Transportation 2016); however, it is anticipated that new changes would alleviate UAS daylight operational restrictions.

The low awareness of UAS technology (average: $3.25 \pm 1.07$ ) among construction professionals was also regarded as a moderately rated barrier of using UASs for construction applications. Despite the extensive research exploring the construction applications of UASs within the last decade, their practical implementation is yet to be fully achieved. However, it is anticipated that with the UAS software and hardware advancements, the emergence of low-cost and easy-to-fly platforms and regulation changes for commercial applications, UAS technology will be widely integrated within the construction industry and the awareness among construction practitioners would become considerably higher in the near future.

Respondents were also moderately concerned about the increased safety challenges (average: $3.18 \pm 1.07$ ) associated with the use of UASs in construction and considered this as a barrier for UAS technology. Flight team members (e.g., pilots, observers) should have a proper understanding of safety challenges associated with using UASs on construction jobsites. To further mitigate these barriers, specific UAS flight mission plans should be developed, and all the parties involved in each flight (e.g., workers, project managers, superintendents, crane operators, safety managers) should be aware and familiar with its details. Survey participants also somewhat acknowledged UASs' restriction to certain types of projects (average: $3.11 \pm 1.19$ ) as another barrier facing UASs integration in construction. However, with advancements in UAS technologies, various types of small- to largesize fixed- and rotatory-wing UAS platforms are available that can be used in a wide range of small to large-sized construction projects.

All other barriers received low ratings with averages between 2.00 and 3.00. The deployment of UASs in the dynamic nature of construction projects (average: $2.89 \pm 1.16$ ) was not regarded as a barrier for using UASs in construction applications. The autonomous features and the advanced hardware components (e.g., high precision positioning systems, high-quality cameras with zooming abilities) allow UASs to acquire data from farther distances from the jobsites, factor that mitigates the barriers associated with the use of UASs in dynamic environments. Although the integration of audio-visual systems in UASs could greatly improve communication on a construction jobsite, participants did not acknowledge the difficulties pertaining to the communication with craft personnel in real-time (average: $2.75 \pm 0.89$ ) as a barrier to UAS adoption. These results are expected since communication with construction workers and craft personnel on the jobsite in real-time is only limited to very specific types of construction activities or tasks and is not a general requirement to all construction applications. Respondents also disagreed that UASs require large capital investment (average: $2.48 \pm 1.21$ ) which is expected facing the low acquisition and maintenance costs associated with the use of the aerial platforms. Finally, practitioners did not consider the lack of regulations pertaining to the safe UAS operational distance (average: 2.39 $\pm 0.96)$ as a barrier to UAS integration in construction. The majority of currently available UASs are typically equipped with obstacle avoidance sensors that can automatically control the safe distance with other obstacles on the jobsite.

The barriers to using UASs in construction were analyzed for reliability and internal consistency using Cronbach's $\alpha$, and for any relevant associations through Pearson correlation. For this set of items, $\alpha$ was equal to 0.818 , which demonstrates the reliability of the obtained results in this part of the questionnaire. As for the correlation analysis, strong correlations $(0.6 \leq \mathrm{r}<0.79)$ were detected between the "increased safety challenges" and "increased liability and legal challenges" as well as "extensive training or certification requirements" and "requires advanced technical know-how" ( $\mathrm{r}=0.75$ and 0.63 ; both $\mathrm{p}<0.001$, respectively) (FIG. 2).

All other barriers displayed lower correlations. Using UASs on construction jobsites might cause hazardous situations, potentially resulting in legal and liability disputes related to issues such as property damages, personal injuries, or even deaths. In addition, UAS pilots should demonstrate a high level of familiarity with the operation 
of UASs and their technicalities so that they safely and efficiently accomplish tasks in such challenging and dynamic environments. Future research should focus on simplifying the operation of UASs by enhancing their user interfaces and improving the efficiency of their onboard payloads (e.g., obstacle avoidance sensors, highaccuracy GPSs). Not only would these improvements help in alleviating the UAS-related safety concerns and the associated liability and legal challenges on the jobsites, but would also enhance this technology's adoption in construction.

TABLE 11: Participants' level of agreement regarding the barriers to using UASs for a construction task

\begin{tabular}{|c|c|c|c|}
\hline \multirow{2}{*}{ \# } & \multirow{2}{*}{ Variables } & \multicolumn{2}{|c|}{ Level of Agreement $^{\mathrm{a}}$} \\
\hline & & Median & Average ( $\sigma)$ \\
\hline 1 & Challenges associated with various weather conditions & 4.00 & $3.95(0.97)$ \\
\hline 2 & Challenges associated with confined or congested areas & 4.00 & $3.88(0.80)$ \\
\hline 3 & Requires advanced technical know-how & 4.00 & $3.52(0.98)$ \\
\hline 4 & Increased liability and legal challenges & 4.00 & $3.48(1.12)$ \\
\hline 5 & Extensive training or certification requirements & 3.00 & $3.34(0.95)$ \\
\hline 6 & Challenges associated with using the technology at night & 3.00 & $3.32(1.12)$ \\
\hline 7 & Low awareness of UAS among construction professionals & 3.00 & $3.25(1.07)$ \\
\hline 8 & Increased safety challenges & 3.00 & $3.18(1.07)$ \\
\hline 9 & Application is limited to certain types of projects & 3.00 & $3.11(1.19)$ \\
\hline 10 & Challenges associated with the dynamic nature of construction projects & 3.00 & $2.89(1.16)$ \\
\hline 11 & Challenges associated with the communication with craft personnel in real-time & 3.00 & $2.75(0.89)$ \\
\hline 12 & Large capital investment & 2.00 & $2.48(1.21)$ \\
\hline 13 & Lack of regulations regarding the safe distance of a UAS (Proximity Issue) & 2.00 & $2.39(0.96)$ \\
\hline
\end{tabular}

${ }^{a}$ Level of Agreement $(1=$ Strongly Disagree and $5=$ Strongly Agree $)$

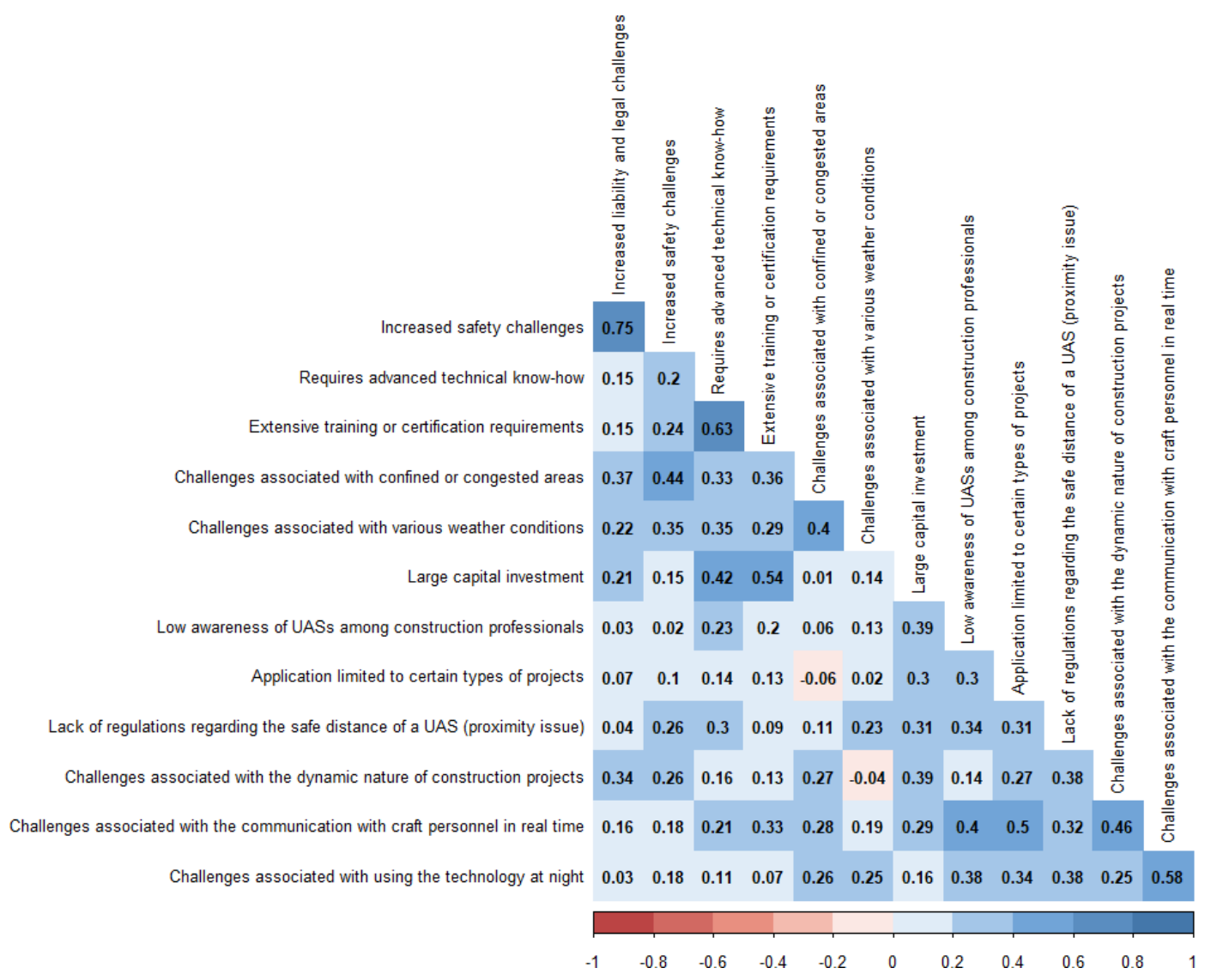

FIG. 2: Matrix diagram showing the correlations among the barriers to UAS integration in construction 


\subsection{Flight Training, Insurance, and Team Members}

This section aims to investigate flight training, insurance, and team members for UAS integration in construction (See Table 12). It should be also mentioned that none of the studies exploring UAS deployment in construction in both academia and industry had yet explored flight training and insurance status as well as flight team members involvement while operating UASs on jobsites. In this context, respondents were first asked to indicate if they were FAA-certified and whether they have previously participated in any FAA Remote Pilot Certificate training program or had any hands-on or virtual UAS flight training. The majority of participants (67\%) were FAA-certified remote pilots; however, less than half of them (44\%) had participated in an FAA Remote Pilot Certificate training program. Some of these training programs were available online or were either internally developed by construction companies or provided through UAS flight training academies and schools. In addition, the majority of the respondents (64\%) indicated that they did not receive any training for hands-on flights, and a significant majority (91\%) did not have any flight training through simulators or other virtual techniques. The FAA does not currently require pilots to demonstrate any practical flight capabilities or hands-on experience pertaining to UAS flight and operation (US Department of Transportation 2016). However, it is of extreme importance to assertively and safely use UASs, especially in construction environments where several factors (e.g., weather, confined or congested areas, populated areas, dynamic nature of jobsites) might negatively affect pilots' navigational capabilities and result in unsafe or life-threatening situations. Implementing hands-on and practical training programs are recommended to ensure that pilots have acquired the proper skills to operate UASs safely and assertively on construction jobsites. The cost of UAS hardware and liability and safety concerns might hinder the opportunities of using physical UASs to conduct hands-on training. As an alternative, virtual simulators should be further developed and integrated to provide construction professionals with training practices to develop their UAS flight skills in a repeatable, risk-free, and controlled environment. Such hands-on or virtual flight experiences could ultimately improve UAS safe and successful adoption in construction.

To further explore the insurance status of UASs in construction, practitioners were asked to specify whether they had any insurance specifically for the UAS flights on their projects. The majority of the participants (79\%) had their aerial platforms insured for accidental damage and liability protection. In a dynamic environment of construction jobsites, UASs are more susceptible to crashes that possibly result in UAS and associated equipment damage, property damage, or even injuries to UAS crew members or workers. Despite the continuous efforts made by the insurance industry to fully cover the commercial deployment of UASs, the risks associated with the use of this relatively new technology are yet to be fully identified and integrated in insurance policies (Herrmann 2016; Zhou et al. 2018). These results show the practitioners' awareness of UAS-associated safety hazards and liability issues on the jobsites and their persistence to cover their platforms, despite the absence of all-inclusive insurance policies covering the risks of using UASs for civilian applications (Zhou et al. 2018).

TABLE 12: Participants' responses regarding their current flight training and insurance status

\begin{tabular}{lll}
\hline Training and Insurance Questions & Yes & No \\
\hline Have you received the FAA (Federal Aviation Administration) Remote Pilot Certificate? & N (\%) & N (\%) \\
\hline Have you participated in any FAA Remote Pilot Certificate training program? & $37(67 \%)$ & $18(33 \%)$ \\
\hline Have you received any training for hands-on UAS flights? & $24(44 \%)$ & $30(56 \%)$ \\
\hline Have you received any UAS flight training through simulators or other virtual techniques? & $20(36 \%)$ & $35(64 \%)$ \\
\hline Do you have any insurance specifically for the UAS flights on your projects? & $5(9 \%)$ & $50(91 \%)$ \\
\hline
\end{tabular}

Finally, to better understand the composition of the flight team, participants were asked to indicate the individuals who are involved during a typical UAS flight on the jobsite. A Remote Pilot in Command (RPIC) who has the final authority and responsibility for the operation of the UAS (US Department of Transportation 2016) should be present for all UAS flights on construction jobsites. The majority of respondents (70\%) indicated that they typically include visual observers, and several of them (18\%) indicated the involvement of safety managers during their UAS flights on the jobsite. A visual observer is another crew member that usually assists the RPIC by providing a second set of eyes on the UAS flight operation to avoid any potential air or ground collisions (US Department of Transportation 2016). Safety managers might also accompany UAS flight teams to identify and avoid any unsafe 
practices caused by the use of UASs on construction jobsites. A few respondents also indicated that they might include other entities such as clients, VDC managers, project engineers, and tower crane operators in their flight team. However, the flight team needs to communicate properly with other project entities such as workers, project managers, and superintendents to ensure a safe UAS deployment on construction jobsites.

\section{DISCUSSION}

Although not exclusively targeting construction professionals experienced with UAS technology, the results obtained in published questionnaires compare well with the application trends identified in this study. In fact, construction professionals, safety managers, and other users across the United States, Australia, and New Zealand reported that UAS-captured visuals could be used for as-built documentation, building inspection and maintenance, progress monitoring, site planning, surveying and mapping, marketing or presentation, safety management, security surveillance, quality control, and measurement-related (e.g., earthmoving) tasks (Amirebrahimi et al. 2018; Gheisari and Esmaeili 2019; Hubbard and Hubbard 2017; Tatum and Liu 2017). Our results are also in accordance with the literature, which shows that UASs are being used for building inspection and maintenance, progress monitoring, site surveying and mapping, safety management, and airflow monitoring (Zhou and Gheisari 2018). In addition to all of the aforementioned applications, our findings identified other UAS applications, including post-disaster reconnaissance, aerial construction, material handling, and site communication, as well as some other specific tasks. These results reflect the expansion of UAS technology in construction and highlight its increasing trends over time. Considering the results of both previous and the present analyses, and the continuous developments in UAS configurations, it is only a matter of time before UAS technology becomes a standardized tool that several construction activities and tasks could benefit from on jobsites. However, recently discovered applications such as aerial construction, material handling, and site communication, require additional testing to ensure effective and safe UAS deployment in this setting.

In terms of the trends in UAS technologies, none of the published questionnaires had focused on the UAS types and models used on jobsites. However, multiple literature reviews corroborate our findings by highlighting rotarywing vehicles as the most frequently deployed aerial platform type, and DJI ${ }^{\circledR}$ as the top manufacturer in the research domain (Albeaino et al. 2019; Zhou and Gheisari 2018). In addition, except for two industry reports (Amirebrahimi et al. 2018; JBKnowledge 2019), all other surveys and academic investigations did not explore the software tools used by industry practitioners on construction jobsites. Yet, the results pertaining to the UAS software in both reports are consistent with our findings. In fact, Amirebrahimi et al. (2018) indicated that Pix4D® is the mostly used software tool by UAS operators in Australia and New Zealand, with both Propeller® and DroneDeploy® ranked among the top five platforms. Another industry report from the United States aiming at exploring technological trends in the construction domain consistently indicated that DroneDeploy ${ }^{\circledR}$, Pix $4 \mathrm{D} ®$, and Skycatch ${ }^{\circledR}$ are among the most frequently used software tools for UAS management and control (JBKnowledge 2019). Despite multiple reviews highlighting the flying styles (i.e., autonomous, semi-autonomous, and manual) adopted by researchers in their studies (Albeaino et al. 2019; Zhou and Gheisari 2018), no research or industry report has yet fully investigated the flight autonomy features utilized by construction practitioners during the UAS deployment, which was one of our study's aims. Also, none of the studies had comprehensively explored the types of data acquired and sensors mounted in construction, apart from one survey reporting video and image capture as the top UAS application in construction (Hubbard and Hubbard 2017). However, our results are consistent with the outcomes of very recent literature reviews (Albeaino et al. 2019; Zhou and Gheisari 2018) which reported that visual and thermal cameras are the most common types of sensors implemented in the research domain. In Australia and New Zealand, UAS users are also mounting visual camera sensors and LiDAR devices for their various UAS-mediated construction applications (Amirebrahimi et al. 2018).

Previous academic literature reviews have indicated similar benefits of using UASs in construction due to their quick, flexible, cost-efficient, accurate, and safe deployment characteristics (Albeaino et al. 2019; Zhou and Gheisari 2018). Likewise, the findings of the current study also corroborate other surveys reporting the practitioners' perspectives on the benefits of UAS usage in construction (Gheisari and Esmaeili 2019; Kim et al. 2016; Tatum and Liu 2017), two of which placed a particular emphasis on the application of UASs in construction safety (Gheisari and Esmaeili 2019; Kim et al. 2016). Such benefits included better accessibility to compromised spaces, advancements in the work quality (e.g., using aerial platforms for jobsite monitoring), as well as improvements in terms of cost, time, and safety. The fact that both academic and industry-based survey studies 
concur with similar UAS beneficial characteristics is of particular relevance, as it reflects a collective agreement on the importance of this technology's usage in construction.

All barriers identified in the current analysis were similar to the ones reported to date from an academic- and industry-based perspective. For example, a recent comprehensive literature review summarized around sixty articles while highlighting major barriers to UAS integration in construction (Golizadeh et al. 2019a). Despite focusing on the academic domain, it identified barriers that compare well with the ones found in the current analysis, specifically targeting construction practitioners who had used this technology on the jobsites in the United States. Some of those (e.g., challenges associated with weather conditions and confined or congested areas, advanced technical know-how requirements) were also discussed in other literature reviews (Albeaino et al. 2019; Zhou and Gheisari 2018). In addition, other industry surveys focusing on how UASs are being used from the perspectives of construction practitioners and safety managers in the United States have also indicated very similar barriers (Gheisari and Esmaeili 2019; Hubbard and Hubbard 2017; Kim et al. 2016; Tatum and Liu 2017).

\section{RESEARCH LIMITATIONS}

The study limitations are twofold: (1) small sample size; and (2) utilized recruitment strategy. The size of the studied population is relatively small and predominantly from the building construction sector in the United States. It is therefore necessary to be cautious when generalizing current study findings. Although relatively small, the sample size could be justified by the facts that: (1) UAS technology adoption in the construction domain is still at an early stage and did not emerge until very recently (Albeaino et al. 2019; Gheisari and Esmaeili 2019; Zhou and Gheisari 2018); and (2) the study's targeted audience (i.e., construction professionals who used UAS technology for construction-related applications across the United States) is currently difficult to recruit, restricted, and hardto-reach, especially when specific publicly-available databases are not available. However, considering that the population of construction professionals who adopted UASs is much smaller than the ones utilizing other more dominant technologies (e.g., BIM, CAD, Virtual Reality), the sample size of the study seems sufficient enough and even similar to the populations reported by other questionnaires (Becerik-Gerber and Kensek 2010; Gheisari and Irizarry 2016; Liu and Issa 2013; Whyte et al. 1999). Additional investigations are warranted to corroborate these findings with larger-scale studies exploring UAS use in other construction sectors in the United States and other countries. It should also be noted that with the tremendous technical improvements and regulation changes that UASs are currently witnessing, the use of UAS technology in the construction domain might significantly increase in the upcoming years. Therefore, to document such changes, a similar study should be conducted in a few years to compare its results with the ones obtained from the present survey. Additionally, the adopted snowball sampling strategy which is considered a non-probability recruitment method could be subject to biases, in that the recruited sample might reflect individuals with a specific opinion regarding the evaluated subject, potentially skewing the findings of this study (Johnson 2014; Sadler et al. 2010; Valerio et al. 2016). However, this strategy was still chosen given the facts that: (1) other probability sampling techniques that could have been used otherwise do not ensure unbiased results (Sadler et al. 2010); and (2) that by sharing similar characteristics, this study's population (i.e., construction professionals in the United States who applied UASs on jobsites) is very restricted and hard-to-reach. The snowball sampling technique also lacks control over the sampling process, since prospective participants are recruited by previous respondents. However, the recruitment strategy utilized in this study specifically targets special populations (Johnson 2014), potentially generating an inherent screening tool that ensures a very selective, yet intended, participant enrollment.

\section{CONCLUSION}

This study aimed to present current application trends of UASs, their adopted technologies, as well as the benefits and barriers to their integration in the construction domain. For this purpose, an online survey was designed and distributed to construction industry practitioners across the United States who had practically used UASs on their construction jobsites to accomplish construction-related tasks. The analysis of 56 responses revealed that the important UAS application areas in construction were progress monitoring, site mapping and surveying, and site planning. In terms of the adopted technologies, rotary-wing vehicles were the most popular type of platforms, DroneDeploy ${ }^{\circledR}$ was the most frequently used software, and auto-return home, auto takeoff/landing, and obstacle avoidance were the most frequently used flight autonomy features in construction. In terms of data type and UAS sensors, images and videos were the main types of acquired data, and visual and thermal cameras were the predominant types of sensors that were used for construction applications. Respondents also agreed that UASs 
could save time and cost while improving accessibility to compromised spaces on construction jobsites. The results of the study also suggested that flying in various weather conditions or in confined or congested areas are the two most highly rated barriers to using UASs for construction applications.

Although very limited, previously published survey studies have focused mainly on: (1) the current and future potential use of UASs in construction; (2) the factors that would affect this technology's performance in safety management and general construction applications; (3) the enablers and barriers to using UASs in this setting; as well as (4) the potential of UAS technology in improving safety management applications. However, none of those studies had targeted a very specific population of construction professionals who had previously used UASs on their jobsites. In addition, the current investigation provides a timely extension to previous conceptual-based studies by empirically investigating the trends in real-world UAS applications throughout the entire construction lifecycle, the commonly used technologies by industry practitioners (i.e., UAS vehicle types, incorporated software tools, flight autonomy features, mounted sensors, and types of retrieved data), and the current flight training, insurance status, and UAS flight team composition. The specific contribution of this research to the construction industry is to highlight practical trends in UAS applications and technologies as well as the benefits and barriers associated with UAS usage based on the construction practitioners' perspectives, ideally improving the integration of UAS technology in construction.

The practical implications of this research would benefit both construction researchers and professionals exploring the use of UASs in construction. Practitioners can benefit from the results of this paper to identify the application areas of UASs in construction and understand their technical requirements and barriers to their successful adoption in the industry. The findings of this study also enable researchers to better identify the industry needs and guides them in investigating application areas or resolving implementation barriers that might have maximum benefits for construction professionals. Technological companies may also rely on this study's results to identify practitioner-reported opportunities and requirements while designing specific solutions to improve UAS implementation in this setting. The findings could finally guide regulatory authorities and insurance companies in developing construction-specific legislations and all-inclusive policies that could ultimately regulate UAS usage and facilitate its safe and ethical adoption in the domain. UAS technology is expected to have a significant impact on the construction industry, and its deployment is more likely to become even more popular. A similar study with a larger sample size should be conducted in a few years to compare its results with the ones obtained from this survey study to observe the changes in UAS implementation in construction. In the future, studies are needed to investigate methodologies, best practices, advantages, and limitations of UAS technology in various construction processes and comparing them with conventional UAS-less approaches. More specifically, future studies should focus on assessing the implementation barriers of newly discovered practical applications (i.e., aerial construction, material handling, and site communication) and optimizing the technical UAS configurations (i.e., software and hardware) to overcome the barriers encountered by professionals and improve this technology's practical deployment in the domain. Also, future studies should combine UASs with other techniques and technologies such as artificial intelligence, machine learning, VR, AR, wearable technologies, and BIM with the aim of enhancing current UAS-mediated applications and exploring new areas that UASs could be of potential benefit in construction.

\section{ACKNOWLEDGMENTS}

The authors thank Shi Zhou and Dr. Robert Ries from Rinker School of Construction Management at the University of Florida and FMI Corporation for helping with the survey review and distribution. We would also like to extend this acknowledgement to all construction professionals who provided their responses to this questionnaire. 


\section{REFERENCES}

Adams, S. M., Levitan, M. L., and Friedland, C. J. (2014). "High Resolution Imagery Collection for Post-Disaster Studies Utilizing Unmanned Aircraft Systems (UAS).” Photogrammetric Engineering \& Remote Sensing, 80(12), 1161-1168.

Agung Pratama, L., Fardsosseini, F., and Lin, K. (2018). “An Overview Of Generating VR Models For Disaster Zone Reconstruction Using Drone Footage." 18th International Conference on Construction Applications of Virtual Reality.

Albeaino, G., Gheisari, M., and Franz, B. W. (2019). "A systematic review of unmanned aerial vehicle application areas and technologies in the AEC domain." Journal of Information Technology in Construction (ITcon), $24,381-405$.

Álvares, J. S., and Costa, D. B. (2019). "Construction Progress Monitoring Using Unmanned Aerial System and 4D BIM." Proc. 27th Annual Conference of the International Group for Lean Construction (IGLC), Dublin, Ireland, 1445-1456.

Amirebrahimi, S., Quadros, N., Coppa, I., and Keysers, J. (2018). UAV Data Acquisition in Australia and New Zealand: User Needs Report. FrontierSI, 113.

Banaszek, A., Zarnowski, A., Cellmer, A., and Banaszek, S. (2017). "Application of New Technology Data Acquisition Using Aerial (UAV) Digital Images for the Needs of Urban Revitalization." Environmental Engineering 10th International Conference, Lithuania.

Barmpounakis, E., and Geroliminis, N. (2020). "On the new era of urban traffic monitoring with massive drone data: The pNEUMA large-scale field experiment." Transportation Research Part C: Emerging Technologies, 111, 50-71.

Becerik-Gerber, B., and Kensek, K. (2010). "Building Information Modeling in Architecture, Engineering, and Construction: Emerging Research Directions and Trends." Journal of Professional Issues in Engineering Education and Practice, 136(3), 139-147.

Bhandari, B., and Park, G. (2020). "Development of a real-time security management system for restricted access areas using computer vision and deep learning." Journal of Transportation Safety \& Security, Taylor \& Francis, 1-16.

Bulatov, D., Solbrig, P., Gross, H., Wernerus, P., Repasi, E., and Heipke, C. (2011). "Context-based urban terrain reconstruction from uav-videos for geoinformation applications." International Conference on Unmanned Aerial Vehicle in Geomatics (UAV-g).

Bürkle, A., Segor, F., and Kollmann, M. (2011). "Towards Autonomous Micro UAV Swarms." Journal of Intelligent \& Robotic Systems, 61(1), 339-353.

Chen, K., Reichard, G., Akanmu, A., and Xu, X. (2021). "Geo-registering UAV-captured close-range images to GIS-based spatial model for building façade inspections.” Automation in Construction, 122, 103503.

Choi, J. O., and Kim, D. B. (2019). "A New UAV-based Module Lifting and Transporting Method: Advantages and Challenges." Proceedings of the 36th International Symposium on Automation and Robotics in Construction (ISARC), M. Al-Hussein, ed., International Association for Automation and Robotics in Construction (IAARC), Banff, Canada, 645-650.

Costin, A., Pradhananga, N., and Teizer, J. (2012). "Leveraging passive RFID technology for construction resource field mobility and status monitoring in a high-rise renovation project." Automation in Construction, 24, 115.

Cronbach, L. J. (1951). "Coefficient alpha and the internal structure of tests." Psychometrika, 16(3), 297-334.

Duque, L., Seo, J., and Wacker, J. (2018). “Bridge Deterioration Quantification Protocol Using UAV.” Journal of Bridge Engineering, 23(10), 04018080.

Eiris Pereira, R., Zhou, S., and Gheisari, M. (2018). "Integrating the Use of UAVs and Photogrammetry into a Construction Management Course: Lessons Learned." Proceedings of the 35th International Symposium on Automation and Robotics in Construction. 
Eiris, R., Albeaino, G., Gheisari, M., Benda, B., and Faris, R. (2020). "Indrone: Visualizing Drone Flight Patterns for Indoor Building Inspection Tasks." Proceedings of the 20th International Conference on Construction Applications of Virtual Reality, Teesside University Press, Middlesbrough, UK, 273-282.

Ellenberg, A., Kontsos, A., Bartoli, I., and Pradhan, A. (2014). "Masonry Crack Detection Application of an Unmanned Aerial Vehicle." Computing in Civil and Building Engineering (2014), American Society of Civil Engineers, Reston, VA, 1788-1795.

Enríquez, C., Jurado, J. M., Bailey, A., Callén, D., Collado, M. J., Espina, G., Marroquín, P., Oliva, E., Osla, E., Ramos, M. I., Sarceño, S., and Feito, F. R. (2020). "The UAS-Based 3D Image Characterization of Mozarabic Church Ruins in Bobastro (Malaga), Spain.” Remote Sensing, Multidisciplinary Digital Publishing Institute, 12(15), 2377.

Eschmann, C., Kuo, C.-M., Kuo, C.-H., and Boller, C. (2012). “Unmanned Aircraft Systems for Remote Building Inspection and Monitoring." 6th European Workshop on Structural Health Monitoring - Th.2.B.1.

Evans, J. D. (1996). Straightforward statistics for the behavioral sciences. Pacific Grove : Brooks/Cole Pub. Co., (C)1996.

Ezequiel, C. A. F., Cua, M., Libatique, N. C., Tangonan, G. L., Alampay, R., Labuguen, R. T., Favila, C. M., Honrado, J. L. E., Canos, V., Devaney, C., Loreto, A. B., Bacusmo, J., and Palma, B. (2014). "UAV aerial imaging applications for post-disaster assessment, environmental management and infrastructure development.” 2014 International Conference on Unmanned Aircraft Systems (ICUAS), IEEE, 274-283.

Finn, R. L., and Wright, D. (2012). "Unmanned aircraft systems: Surveillance, ethics and privacy in civil applications." Computer Law \& Security Review, 28(2), 184-194.

Gheisari, M., and Esmaeili, B. (2019). "Applications and requirements of unmanned aerial systems (UASs) for construction safety." Safety Science, 118, 230-240.

Gheisari, M., and Irizarry, J. (2016). "Investigating human and technological requirements for successful implementation of a BIM-based mobile augmented reality environment in facility management practices." Facilities, 34(1/2), 69-84.

Gheisari, M., Rashidi, A., and Esmaeili, B. (2018). "Using Unmanned Aerial Systems for Automated Fall Hazard Monitoring." Construction Research Congress 2018, American Society of Civil Engineers, New Orleans, Louisiana, 62-72.

Goessens, S., Mueller, C., and Latteur, P. (2018). "Feasibility study for drone-based masonry construction of realscale structures." Automation in Construction, 94, 458-480.

Golizadeh, H., Hosseini, M. R., Edwards, D. J., Abrishami, S., Taghavi, N., and Banihashemi, S. (2019a). "Barriers to adoption of RPAs on construction projects: a task-technology fit perspective." Construction Innovation, Emerald Publishing Limited, 19(2), 149-169.

Golizadeh, H., M. Hosseini, R., Martek, I., Edwards, D., Gheisari, M., Banihashemi, S., and Zhang, J. (2019b). "Scientometric analysis of research on 'remotely piloted aircraft': A research agenda for the construction industry." Engineering, Construction and Architectural Management, Emerald Publishing Limited, 27(3), $634-657$.

González-deSantos, L. M., Martínez-Sánchez, J., González-Jorge, H., Navarro-Medina, F., and Arias, P. (2020). "UAV payload with collision mitigation for contact inspection." Automation in Construction, 115, 103200.

Hair, J. F., Black, W. C., Babin, B. J., and Anderson, R. E. (2014). Multivariate data analysis. Pearson custom library, Pearson, Harlow.

Hallermann, N., and Morgenthal, G. (2013). "Unmanned aerial vehicles (UAV) for the assessment of existing structures.” 36th IABSE Symposium, 1-8.

Hallermann, N., Morgenthal, G., and Rodehorst, V. (2015a). "Unmanned Aerial Systems (UAS)-Case Studies of Vision Based Monitoring of Ageing Structures." International Symposium Non-Destructive Testing in Civil Engineering (NDT-CE). 
Hallermann, N., Morgenthal, G., and Rodehorst, V. (2015b). "Vision-based monitoring of heritage monuments: Unmanned Aerial Systems (UAS) for detailed inspection and high-accuracy survey of structures.” 14th International Conference on Studies, Repairs and Maintenance of Heritage Architecture, 621-632.

Hart, W. S., and Gharaibeh, N. G. (2011). "Use of Micro Unmanned Aerial Vehicles in Roadside Condition Surveys." Transportation and Development Institute Congress 2011, American Society of Civil Engineers, Reston, VA, 80-92.

Hassanalian, M., and Abdelkefi, A. (2017). "Classifications, applications, and design challenges of drones: A review." Progress in Aerospace Sciences, 91(May), 99-131.

Herrmann, M. (2016). "Unmanned Aerial Vehicles in Construction: An Overview of Current and Proposed Rules." Construction Research Congress 2016, Proceedings, 588-596.

Herrmann, M. (2018). "Regulation of Unmanned Aerial Vehicles and a Survey on Their Use in the Construction Industry.” Construction Research Congress 2018, American Society of Civil Engineers, 758-764.

Hubbard, B., Wang, H., Leasure, M., Ropp, T., Lofton, T., Hubbard, S., and Lin, S. (2015). "Feasibility Study of UAV use for RFID Material Tracking on Construction Sites." 51st ASC Annual International Conference Proceedings.

Hubbard, S., and Hubbard, B. (2017). "UAS in the Construction Industry.” ICCREM 2016: BIM Application and Off-Site Construction, American Society of Civil Engineers, 2017, Reston, VA, 187-193.

Hugenholtz, C. H., Walker, J., Brown, O., and Myshak, S. (2015). "Earthwork Volumetrics with an Unmanned Aerial Vehicle and Softcopy Photogrammetry." Journal of Surveying Engineering, American Society of Civil Engineers, 141(1), 06014003.

Irizarry, J., and Costa, D. B. (2016). "Exploratory Study of Potential Applications of Unmanned Aerial Systems for Construction Management Tasks.” Journal of Management in Engineering, 32(3), 05016001.

Irizarry, J., Gheisari, M., and Walker, B. N. (2012). "Usability assessment of drone technology as safety inspection tools." Journal of Information Technology in Construction (ITcon), 17(September), 194-212.

JBKnowledge. (2019). The 2019 Annual Construction Technology Report. JBKnowledge.

Jiang, W., Zhou, Y., Ding, L., Zhou, C., and Ning, X. (2020a). "UAV-based 3D reconstruction for hoist site mapping and layout planning in petrochemical construction.” Automation in Construction, 113, 103137.

Jiang, Y., Liang, W., and Geng, P. (2020b). “Application research on slope deformation monitoring and earthwork calculation of foundation pits based on UAV oblique photography." IOP Conference Series: Earth and Environmental Science, IOP Publishing, 580, 012053.

Johnson, T. P. (2014). “Snowball Sampling: Introduction.” Wiley StatsRef: Statistics Reference Online, American Cancer Society.

Kang, D., and Cha, Y.-J. (2018). “Autonomous UAVs for Structural Health Monitoring Using Deep Learning and an Ultrasonic Beacon System with Geo-Tagging." Computer-Aided Civil and Infrastructure Engineering, 33(10), 885-902.

Kim, D. H., Kwon, S. W., Jung, S. W., Park, S., Park, J. W., and Seo, J. W. (2015). “A Study on Generation of 3D Model and Mesh Image of Excavation Work using UAV." ISARC. Proceedings of the International Symposium on Automation and Robotics in Construction; Waterloo, IAARC Publications, Waterloo, Canada, Waterloo, 1-7.

Kim, S., and Irizarry, J. (2019). "Human Performance in UAS Operations in Construction and Infrastructure Environments.” Journal of Management in Engineering, 35(6), 04019026.

Kim, S., Irizarry, J., and Costa, D. B. (2016). "Potential Factors Influencing the Performance of Unmanned Aerial System (UAS) Integrated Safety Control for Construction Worksites.” Construction Research Congress 2016, American Society of Civil Engineers, San Juan, Puerto Rico, 2614-2623.

Kim, S., Paes, D., Lee, K., Irizarry, J., and Johnson, E. N. (2019). “UAS-Based Airport Maintenance Inspections: Lessons Learned from Pilot Study Implementation.” Computing in Civil Engineering, 382-389. 
Koutsoudis, A., Vidmar, B., Ioannakis, G., Arnaoutoglou, F., Pavlidis, G., and Chamzas, C. (2014). "Multi-image 3D reconstruction data evaluation." Journal of Cultural Heritage, 15(1), 73-79.

Kruijff, G. M., Pirri, F., Gianni, M., Papadakis, P., Pizzoli, M., Sinha, A., Tretyakov, V., Linder, T., Pianese, E., Corrao, S., Priori, F., Febrini, S., and Angeletti, S. (2012). "Rescue robots at earthquake-hit Mirandola, Italy: A field report." 2012 IEEE International Symposium on Safety, Security, and Rescue Robotics (SSRR), 1-8.

Lindsey, Q., Mellinger, D., and Kumar, V. (2011). "Construction of Cubic Structures with Quadrotor Teams." Proceedings of Robotics: Science and Systems, Los Angeles, CA, USA.

Lingamaneni, R., Kubitza, T., and Scheible, J. (2017). "DroneCAST: Towards a Programming Toolkit for Airborne Multimedia Display Applications." Proceedings of the 19th International Conference on HumanComputer Interaction with Mobile Devices and Services, MobileHCI '17, Association for Computing Machinery, New York, NY, USA.

Liu, J., Jennesse, M., and Holley, P. (2016). "Utilizing Light Unmanned Aerial Vehicles for the Inspection of Curtain Walls: A Case Study.” Construction Research Congress 2016, American Society of Civil Engineers, Reston, VA, 2651-2659.

Liu, R., and Issa, R. R. A. (2013). "Issues in BIM for Facility Management from Industry Practitioners' Perspectives." American Society of Civil Engineers, Los Angeles, California, United States of America, 411-418.

Martinez, J. G., Albeaino, G., Gheisari, M., Volkmann, W., and Alarcón, L. F. (2021a). "UAS Point Cloud Accuracy Assessment Using Structure from Motion-Based Photogrammetry and PPK Georeferencing Technique for Building Surveying Applications.” Journal of Computing in Civil Engineering, American Society of Civil Engineers, 35(1), 05020004.

Martinez, J. G., Albeaino, G., Gheisari, M., Issa, R. R. A., and Alarcón, L. F. (2021b). "iSafeUAS: An unmanned aerial system for construction safety inspection." Automation in Construction, 125, 103595.

Martinez, J. G., Gheisari, M., and Alarcón, L. F. (2020). "UAV Integration in Current Construction Safety Planning and Monitoring Processes: Case Study of a High-Rise Building Construction Project in Chile." Journal of Management in Engineering, 36(3).

McKinsey\&Company. (2017). Commercial drones are here: The future of unmanned aerial systems.

Mellinger, D., Shomin, M., Michael, N., and Kumar, V. (2010). "Cooperative Grasping and Transport Using Multiple Quadrotors.” Distributed Autonomous Robotic Systems, Springer, Berlin, Heidelberg, Lausanne, Switzerland.

de Melo, R. R. S., Costa, D. B., Álvares, J. S., and Irizarry, J. (2017). “Applicability of unmanned aerial system (UAS) for safety inspection on construction sites.” Safety Science, 98, 174-185.

Merz, T., and Kendoul, F. (2011). "Beyond visual range obstacle avoidance and infrastructure inspection by an autonomous helicopter." 2011 IEEE/RSJ International Conference on Intelligent Robots and Systems, IEEE, 4953-4960.

Michael, N., Fink, J., and Kumar, V. (2011). "Cooperative manipulation and transportation with aerial robots." Autonomous Robots, 30(1), 73-86.

Michael, N., Shen, S., Mohta, K., Mulgaonkar, Y., Kumar, V., Nagatani, K., Okada, Y., Kiribayashi, S., Otake, K., Yoshida, K., Ohno, K., Takeuchi, E., and Tadokoro, S. (2012). "Collaborative mapping of an earthquake-damaged building via ground and aerial robots.” Journal of Field Robotics, John Wiley \& Sons, Ltd, 29(5), 832-841.

Morgenthal, G., and Hallermann, N. (2014). "Quality Assessment of Unmanned Aerial Vehicle (UAV) Based Visual Inspection of Structures." Advances in Structural Engineering, 17(3), 289-302.

Mutis, I., and Romero, A. F. (2019). "Thermal Performance Assessment of Curtain Walls of Fully Operational Buildings Using Infrared Thermography and Unmanned Aerial Vehicles.” Advances in Informatics and Computing in Civil and Construction Engineering, I. Mutis and T. Hartmann, eds., Springer International Publishing, Cham, 703-709. 
Neitzel, F., and Klonowski, J. (2012). "Mobile 3D Mapping With A Low-Cost UAV System." ISPRS International Archives of the Photogrammetry, Remote Sensing and Spatial Information Sciences, Copernicus GmbH, Zurich, Switzerland, 39-44.

Niethammer, U., James, M. R., Rothmund, S., Travelletti, J., and Joswig, M. (2012). "UAV-based remote sensing of the Super-Sauze landslide: Evaluation and results.” Engineering Geology, 128, 2-11.

Park, J. S., Kim, P., Cho, Y. K., and Fang, Y. (2018). “Automated Collaboration Framework of UAV and UGV for 3D Visualization of Construction Sites." 18th International Conference on Construction Applications of Virtual Reality, Auckland.

Püschel, H., Sauerbier, M., Eisenbeiss, H., and L, C. (2008). "A 3D model of Castle Landenberg (CH) from combined photogrammetric processing of terrestrial and UAV-based images." XXIst ISPRS Congress, Beijing.

Qualtrics. (2019). Qualtrics. Provo, Utah, USA.

Roberts, D., Bretl, T., and Golparvar-Fard, M. (2017). "Detecting and Classifying Cranes Using Camera-Equipped UAVs for Monitoring Crane-Related Safety Hazards." Computing in Civil Engineering 2017, American Society of Civil Engineers, Reston, VA, 442-449.

Roca, D., Lagüela, S., Díaz-Vilariño, L., Armesto, J., and Arias, P. (2013). "Low-cost aerial unit for outdoor inspection of building façades." Automation in Construction, 36, 128-135.

RStudio Team. (2019). RStudio: Integrated Development Environment for R. RStudio, Inc., Boston, MA.

Sadler, G. R., Lee, H.-C., Lim, R. S.-H., and Fullerton, J. (2010). "Research Article: Recruitment of hard-to-reach population subgroups via adaptations of the snowball sampling strategy." Nursing \& Health Sciences, 12(3), 369-374.

Scheible, J., and Funk, M. (2016). "In-Situ-Displaydrone: Facilitating Co-Located Interactive Experiences via a Flying Screen." Proceedings of the 5th ACM International Symposium on Pervasive Displays, PerDis '16, Association for Computing Machinery, New York, NY, USA, 251-252.

Schneegass, S., Alt, F., Scheible, J., and Schmidt, A. (2014). "Midair Displays: Concept and First Experiences with Free-Floating Pervasive Displays." Proceedings of The International Symposium on Pervasive Displays, PerDis '14, Association for Computing Machinery, New York, NY, USA, 27-31.

Shakhatreh, H., Sawalmeh, A. H., Al-Fuqaha, A., Dou, Z., Almaita, E., Khalil, I., Othman, N. S., Khreishah, A., and Guizani, M. (2019). "Unmanned Aerial Vehicles (UAVs): A Survey on Civil Applications and Key Research Challenges.” IEEE Access, 7, 48572-48634.

Siebert, S., and Teizer, J. (2013). "Mobile 3D Mapping for Surveying Earthwork Using an Unmanned Aerial Vehicle (UAV)." Proceedings of the 30th International Symposium on Automation and Robotics in Construction and Mining (ISARC 2013): Building the Future in Automation and Robotics, F. Hassani, O. Moselhi, and C. Haas, eds., International Association for Automation and Robotics in Construction (IAARC), Montreal, Canada, 1366-1375.

Siebert, S., and Teizer, J. (2014). "Mobile 3D mapping for surveying earthwork projects using an Unmanned Aerial Vehicle (UAV) system." Automation in Construction, 41, 1-14.

Taber, K. S. (2018). "The Use of Cronbach's Alpha When Developing and Reporting Research Instruments in Science Education.” Research in Science Education, 48(6), 1273-1296.

Tatum, M. C., and Liu, J. (2017). "Unmanned Aircraft System Applications in Construction." Creative Construction Conference 2017, CCC 2017, 19-22 June 2017, Primosten, Croatia, 196, 167-175.

Tavakol, M., and Dennick, R. (2011). "Making sense of Cronbach's alpha.” International Journal of Medical Education, 2, 53-55.

Unger, J., Reich, M., and Heipke, C. (2014). “UAV-based photogrammetry: monitoring of a building zone.” ISPRS - International Archives of the Photogrammetry, Remote Sensing and Spatial Information Sciences, XL5, 601-606.

US Department of Transportation. (2016). Advisory Circular 107-2 - Small Unmanned Aircraft Systems (sUAS). 
Uysal, M., Polat, N., Uysal, M., Toprak, A. S., Polat A A Afyon, N., Üniversitesi, K., Fakültesi, M., Mühendisliği, H., Afyon, B., Meslek, U. E., and Okulu, Y. (2013). "Photo Realistic 3D Modeling With UAV: Gedik Ahmet Pasha Mosque In Afyonkarahisar.” XXIV International CIPA Symposium, Stratsbourg.

Valerio, M. A., Rodriguez, N., Winkler, P., Lopez, J., Dennison, M., Liang, Y., and Turner, B. J. (2016). "Comparing two sampling methods to engage hard-to-reach communities in research priority setting." BMC Medical Research Methodology, 16(1), 146-146.

Wang, X., Al-Shabbani, Z., Sturgill, R., Kirk, A., and Dadi, G. B. (2017). "Estimating Earthwork Volumes Through Use of Unmanned Aerial Systems." Transportation Research Record, SAGE Publications Inc, 2630(1), 1-8.

Wefelscheid, C., Hänsch, R., and Hellwich, O. (2011). "Three-Dimensional Building Reconstruction Using Images Obtained by Unmanned Aerial Vehicles." International Conference on Unmanned Aerial Vehicle in Geomatics (UAV-g), 183-188.

Wen, M.-C., and Kang, S.-C. (2014). “Augmented Reality and Unmanned Aerial Vehicle Assist in Construction Management." Computing in Civil and Building Engineering (2014), American Society of Civil Engineers, Orlando, Florida, United States, 1570-1577.

Whyte, J., Bouchlaghem, N., Thorpe, A., and Mccaffer, R. (1999). “A survey of CAD and virtual reality within the house building industry." Engineering, Construction and Architectural Management, 6(4), 371-379.

Williamson III, K., and Gage, G. (2019). "Important Considerations for Implementing a Drone-based Activity within a Construction Surveying Course." 55th ASC Annual International Conference Proceedings, Denver, Colorado.

Xu, Y., and Turkan, Y. (2018). "Bridge Inspection Using Bridge Information Modeling (BrIM) and Unmanned Aerial System (UAS).” Proceedings of the 35th CIB W78 2018 Conference: IT in Design, Construction, and Management, Springer International Publishing, Chicago, 617-624.

Yeh, T. W., and Chuang, R. Y. (2020). "Morphological Analysis of Landslides in Extreme Topography by UASSfM: Data Acquisition, 3D Models and Change Detection." The International Archives of Photogrammetry, Remote Sensing and Spatial Information Sciences, Copernicus GmbH, Gottingen, XLIII-B5-2020, 173-178.

Yuan, P., Bare, M. G., Johnson, M. O., and Saberi, P. (2014). "Using Online Social Media for Recruitment of Human Immunodeficiency Virus-Positive Participants: A Cross-Sectional Survey.” Journal of Medical Internet Research, 16(5), e117-e117.

Zhang, R., Li, H., Duan, K., You, S., Liu, K., Wang, F., and Hu, Y. (2020). “Automatic Detection of EarthquakeDamaged Buildings by Integrating UAV Oblique Photography and Infrared Thermal Imaging." Remote Sensing, Multidisciplinary Digital Publishing Institute, 12(16), 2621.

Zhou, S., and Gheisari, M. (2018). "Unmanned aerial system applications in construction: a systematic review." Construction Innovation, CI-02-2018-0010.

Zhou, Z., Irizarry, J., and Lu, Y. (2018). “A Multidimensional Framework for Unmanned Aerial System Applications in Construction Project Management." Journal of Management in Engineering, 34(3), 04018004-04018004. 